\title{
Genome-wide analysis of the Saccharina japonica sulfotransferase genes and their transcriptional profiles during whole developmental periods and under abiotic stresses
}

Chang Lu $u^{1,2,3}$, Zhanru Shao ${ }^{1,2^{*}}$, Pengyan Zhang ${ }^{2,4}$ and Delin Duan ${ }^{1,2,5^{*}}$ (D)

\begin{abstract}
Background: As a unique sulfated polysaccharide, fucoidan is an important component of cell wall in brown seaweeds. Its biochemical properties are determined by the positions and quantity of sulfate groups.

Sulfotransferases (STs) catalyze the sulfation process, which transfer the sulfuryl groups to carbohydrate backbones and are crucial for fucoidan biosynthesis. Nevertheless, the structures and functions of STs in brown seaweeds are rarely investigated.
\end{abstract}

Results: There are a total of 44 ST genes identified from our genome and transcriptome analysis of Saccharina japonica, which were located in the 17 scaffolds and 11 contigs. The S. japonica ST genes have abundant introns and alternative splicing sites, and five tandem duplicated gene clusters were identified. Generally, the ST genes could be classified into five groups (Group I V) based on phylogenetic analysis. Accordingly, the ST proteins, which were encoded by genes within the same group, contained similar conserved motifs. Members of the $S$. japonica ST gene family show various expression patterns in different tissues and developmental stages. Transcriptional profiles indicate that the transcriptional levels of more than half of the ST genes are higher in kelp basal blades than in distal blades. Except for ST5 and ST28, most ST genes are down-regulated with the kelp development stages. The expression levels of nine ST genes were detected by real-time quantitative PCR, which demonstrates that they responded to low salinity and drought stresses.

Conclusions: Various characteristics of the STs allow the feasibilities of S. japonica to synthesize fucoidans with different sulfate groups. This enables the kelp the potential to adapt to the costal environments and meet the needs of S. japonica growth.

Keywords: Saccharina japonica, Sulfotransferase, Fucoidan, Transcriptome, Genome

\footnotetext{
* Correspondence: zrshao@qdio.ac.cn; dlduan@qdio.ac.cn

${ }^{1}$ Key Laboratory of Experimental Marine Biology, Center for Ocean

Mega-Science, Institute of Oceanology, Chinese Academy of Sciences,

Qingdao 266071, P. R. China

Full list of author information is available at the end of the article
}

(c) The Author(s). 2020 Open Access This article is licensed under a Creative Commons Attribution 4.0 International License, which permits use, sharing, adaptation, distribution and reproduction in any medium or format, as long as you give appropriate credit to the original author(s) and the source, provide a link to the Creative Commons licence, and indicate if changes were made. The images or other third party material in this article are included in the article's Creative Commons licence, unless indicated otherwise in a credit line to the material. If material is not included in the article's Creative Commons licence and your intended use is not permitted by statutory regulation or exceeds the permitted use, you will need to obtain permission directly from the copyright holder. To view a copy of this licence, visit http://creativecommons.org/licenses/by/4.0/ The Creative Commons Public Domain Dedication waiver (http://creativecommons.org/publicdomain/zero/1.0/) applies to the data made available in this article, unless otherwise stated in a credit line to the data. 


\section{Background}

Saccharina japonica is a brown seaweed with high commercial value in Asia. It is rich in crude fibers and carbohydrates and is widely used as a raw material for the extraction of alginate and fucoidan. Moreover, S. japonica contains many bioactive substances that are valuable for cosmetics, foods and health [1]. Among all bioactive metabolites, fucoidan, a sulfated polysaccharide, is considered highly valuable in the field of medicine. For instance, fucoidan exerts immunomodulation, antiinflammation, anti-tumor, anticoagulant and antithrombotic functions [2-5], and is also effective in relieving diabetic nephropathy and adenine-induced chronic kidney disease [6, 7].

Fucoidan, which mainly exists in echinoderm and cell walls of brown algae [8], was first discovered by Kylin in brown algae Laminaria digitata in 1913 [9]. The fucoidan biosynthesis pathway in brown algae was not clear until the release of genome sequences of Ectocarpus siliculosus in 2010 [10]. Based on E. siliculosus genome sequencing and analogized with glycosaminoglycan (GAG) biosynthesis, Michel et al. (2010) deduced that fucoidan may first be polymerized into neutral polysaccharides by fucosyltransferases, and then sulfated by specific sulfotransferases [11]. He proposed two routes of GDPfucose production: 1) fructose-6-phosphate is catalyzed by mannose-6-phosphate isomerase (MPI), phosphomannomutase (PMM) and mannose-1-phosphate guanylyltransferase (MPG) to synthesize GDP-mannose, followed by the production of GDP-fucose, which is catalyzed by GDP-mannose 4, 6-dehydrogenase (GM46D) and the bifunctional enzyme GDP-L-fucoidase synthase (GFS); 2) alternatively, L-fucose is used as the substrate to synthesize GDP-fucose by fucose kinase (FK) and GDP-fucose pyrophosphorylase (GFPP). GDP-fucose is subsequently used to generate fucoidan by fucosyltransferase (FUT) and sulfotransferase (ST). Some genes involved in fucoidan biosynthesis have been investigated in $S$. japonica and Nemacystus decipiens [12, 13]. Chi et al. (2017) explored the gene origin, expression difference and the enzymatic activity of MPI, MPG and PMM in S. japonica [14]. Nishitsuji et al. (2019) confirmed that $F K$ and GFPP fused in $N$. decipiens genome [13]. Zhang et al. (2018) illustrated the expression and purification, enzymatic activity and response to light and temperature stress of PMM/PGM (phosphoglucomutase) in S. japonica [15].

There are many kinds of monosaccharide involved in the biosynthesis process of fucoidan. The main component of the sulfated fucoidan was L-fucose-4-sulfate; galactose, mannose, xylose, glucose, arabinose, and glucuronic acid exist in small amounts $[16,17]$. It was believed that the content and structure of fucoidans in algae vary in different algae species, tissues, age, inhabitance and seasons [18, 19]. The structural parameters of fucoidan, such as the type of monosaccharide and fucose chain and the molecular weight of polysaccharide, all contribute to its bioactivity, especially the number and position of sulfate groups on the macromolecular skeleton [20-22]. For instance, the 2, 3disulfated sugar residue is a common structure for anticoagulant activity [23, 24], whereas, the existence of 2-Osulfation at the $\mathrm{C}-2$ position reduces the anticoagulant activity of fucoidan [25]. Thus, sulfation has an influence on the function of fucoidan. It has been reported that sulfotransferase (ST) transfers the sulfuryl groups from the universal donor $3^{\prime}$-phosphoadenosine $5^{\prime}$-phosphosulfate (PAPS) to carbohydrate backbones [26]. Therefore, sulfotransferase, the crucial enzyme catalyzing the last step of fucoidan biosynthesis determines the position and quantity of sulfate groups in fucoidan. Multiple ST sequences have been annotated in genome of many kinds of algae, e.g. 41 in E. siliculosus and 24 in Cladosiphon okamuranus [10, 27]. Besides, Ye et al. (2015) reconstructed the carbon metabolism pathway in 14 algal genomes [12], and 13 out of 14 species genomes contains $S T$ genes. Considering $S T$ gene family contains large amount of putative members, it is thus necessary to globally analyze the distinct features of these STs in brown algae. However, there is no study on the $S T$ gene family of brown algae so far.

In this study, we screened 104 genes (including three MPIs, two PMMs, three GM46Ds, 22 FUT, 73 ST and one $F K$ ) involved in fucoidan biosynthesis in $S$. japonica. Specifically, we characterized the $S T$ genes by analyzing their sequence features, scaffold locations, phylogenetic relationships, tissue and time specific expression patterns and dynamic transcriptional profiles in response to low salinity and drought abiotic stresses. This is the first study to investigate the characteristics of $S T$ family members in $S$. japonica. Our results provide valuable knowledge of the biosynthesis of sulfated fucoidan in brown seaweeds, and have great potential for in vitro applications of STs in fucoidan synthesis.

\section{Results \\ Identification and expression profiles of fucoidan biosynthetic genes}

A total of 104 genes related to fucoidan biosynthesis were annotated based on our genome and transcriptome databases of S. japonica. Table S1 lists their gene ID, length of sequences and FPKM values (Additional file 1: Table S1). Figure 1 shows the expression levels of corresponding genes. The transcriptional levels of MPI3 (GENE_013986), PMM1 (GENE_007314), GM46D1 (GENE_026041) and ST1 (GENE_011842) were relatively higher in each catalytic step, which were believed to be essential for fucoidan biosynthesis during the kelp growth and development. From the perspective of expression abundance, PMM1 showed the highest FPKM value while all the FUTs were expressed in very low levels. In different development 


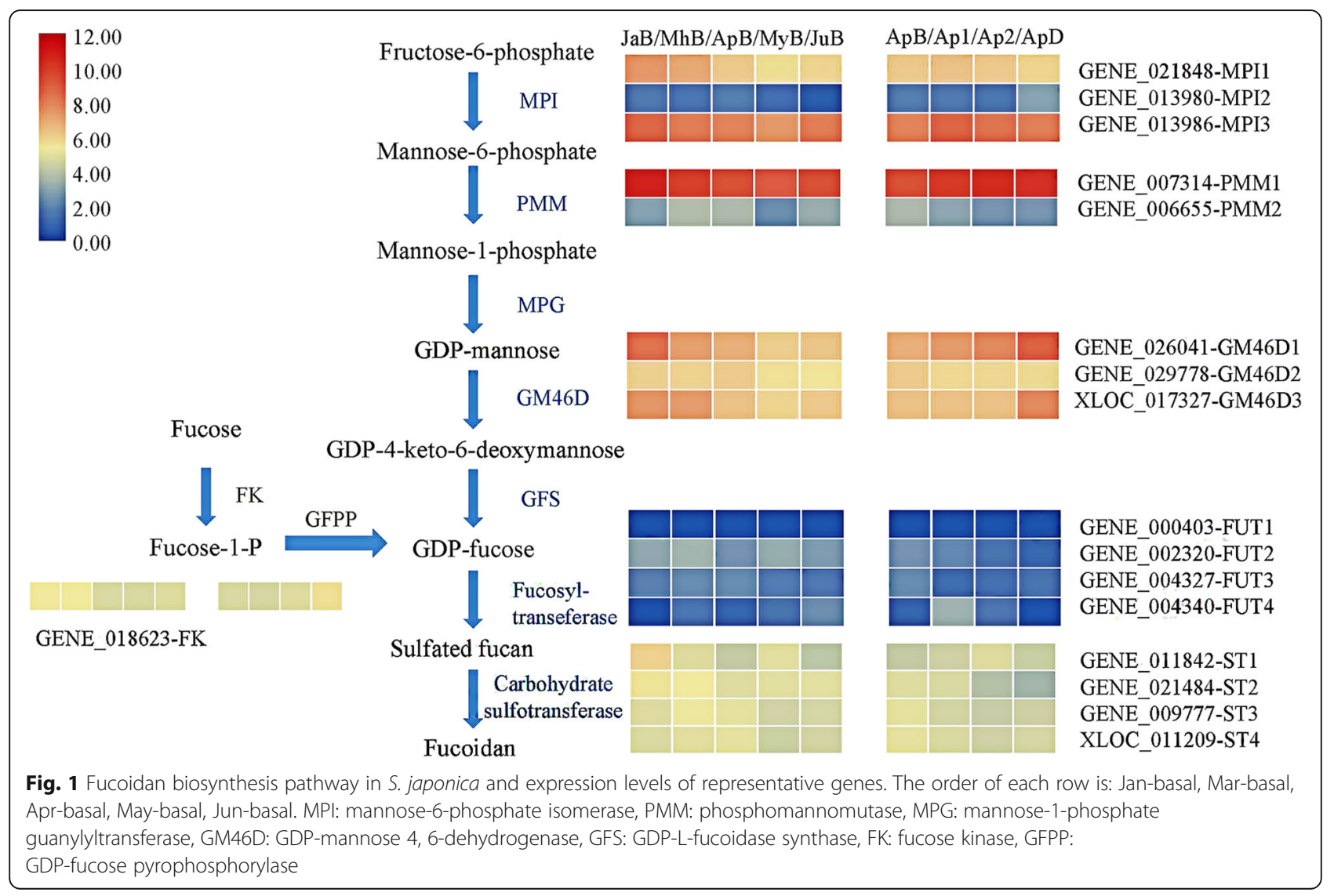

stages, most of these genes were shown a down-regulated trend. In different tissues, MPI2, PMM1, GM46D1, GM46D3 and $F K$ showed up-regulated trends from basal blade to distal blade while PMM2, GM46D2, FUT2, FUT3 were down-regulated.

\section{Identification and sequences characterization of the ST genes}

S. japonica genome had 73 genes automatically annotated as $S T$ genes. After further analysis with Blast, SMART and Pfam database, the sequences with low confidence of sulfotransferase domain and repetitive genes were removed. Finally, 44 sequences were confirmed as S. japonica ST genes, which at least contained one of these domains: Gal-3-O_sulfotr domain (PF06990), Sulfotransfer_1 domain (PF00685), Sulfotransfer-2 domain (PF03567) or Sulfotransfer_3 domain (PF13469).

These $44 \bar{S} T$ genes were named ST1 to ST44 (the average FPKM values from high to low). Name, gene ID, scaffold location, ORF length, exon number, amino acid number, molecular weight, and pI of the 44 genes and their corresponding proteins are summarized in Table 1. The number of amino acids of STs ranged from 82 (ST42) to 514 (ST38), and their molecular weight were from $9.57 \mathrm{kDa}$ (ST42) to 56.82
$\mathrm{kDa}$ (ST38). The predicted isoelectric point (pI) values of ST proteins ranged from 4.66 (ST34) to 10.16 (ST29).

The localization predication of ST proteins shows that they have complex cell compartmentalization (Additional file 2: Table S2). Prediction indicated that $70.45 \%$ proteins were non-secretory. Nine proteins (ST2, ST3, ST16, ST23, ST35, ST37, ST38, ST39 and ST41) have transmembrane helices, which may be located in plasma membrane or endomembrane system. Among them, four STs (ST3, ST16, ST37 and ST38) had signal peptides and two STs (ST2 and ST23) had signal anchors. In addition, seven proteins (ST1, ST4, ST6, ST7, ST10, ST11 and ST25) contained signal peptides without the transmembrane domain. ST2, ST13 and ST26 were predicted to target the chloroplast with high confidence by TargetP, whereas ST3, ST7, ST9, ST14, ST16, ST19, ST22, ST25, ST35, ST38, ST43 and ST44, were predicted to be located in the mitochondria.

\section{Phylogenetic, motif and gene structure analysis of the ST genes}

The $44 S$. japonica ST proteins could be primarily classified into five groups (I - V) (Fig. 2a). A total of 20 conserved motifs were identified by MEME, which length ranged from 21 to 163 amino acids (Fig. 2b and 
Table 1 Features of the S. japonica ST genes and their corresponding proteins

\begin{tabular}{|c|c|c|c|c|c|c|c|c|}
\hline Gene & ID & Scaffolds & Genomic Location & ORF & Exon & AA & MW (kDa) & pls \\
\hline ST1 & GENE_011842 & chr4 & $10,762,476-10,778,806$ & 1272 & 13 & 423 & 48.36 & 5.99 \\
\hline ST2 & GENE_021484 & chr27 & $754,976-771,068$ & 1416 & 8 & 471 & 51.37 & 6.17 \\
\hline ST3 & GENE_009777 & chr15 & $5,230,475-5,248,182$ & 1266 & 10 & 421 & 46.49 & 8.35 \\
\hline ST4 & XLOC_011209 & chr4 & $10,825,718-10,851,003$ & 1266 & 12 & 421 & 48.31 & 5.13 \\
\hline ST5 & GENE_026617 & contig2134 & $6272-25,732$ & 1236 & 9 & 411 & 46.61 & 9.40 \\
\hline ST6 & GENE_013439 & chr4 & $12,759,861-12,768,682$ & 1134 & 5 & 377 & 40.53 & 5.14 \\
\hline ST7 & GENE_011825 & chr4 & $10,671,246-10,701,618$ & 1281 & 13 & 426 & 48.49 & 5.99 \\
\hline ST8 & GENE_026961 & chr10 & $4,062,078-4,075,767$ & 972 & 7 & 323 & 36.23 & 5.88 \\
\hline ST9 & GENE_019245 & contig569 & $94,071-106,934$ & 783 & 8 & 260 & 28.80 & 9.26 \\
\hline ST10 & XLOC_015241 & chr3 & $8,411,455-8,434,996$ & 1050 & 10 & 349 & 38.47 & 5.72 \\
\hline ST11 & GENE_005471 & chr19 & $3,980,992-4,011,984$ & 1296 & 11 & 431 & 48.54 & 5.89 \\
\hline ST12 & XLOC_024652 & chr6 & $11,475,841-11,490,125$ & 942 & 7 & 313 & 35.33 & 6.50 \\
\hline ST13 & GENE_024538 & contig148 & $34,484-58,037$ & 1158 & 11 & 385 & 44.10 & 6.57 \\
\hline ST14 & XLOC_026654 & chr14 & $13,042,373-13,061,909$ & 354 & 3 & 117 & 13.48 & 4.77 \\
\hline ST15 & GENE_016486 & chr29 & $6,287,160-6,299,378$ & 822 & 9 & 273 & 30.81 & 5.96 \\
\hline ST16 & GENE_018833 & chr23 & $7,201,518-7,212,302$ & 948 & 6 & 315 & 34.92 & 7.22 \\
\hline ST17 & GENE_006499 & chr6 & $1,127,751-1,135,830$ & 600 & 6 & 199 & 22.72 & 4.87 \\
\hline ST18 & GENE_017164 & contig3228 & $10,008-34,404$ & 1320 & 8 & 439 & 49.59 & 8.72 \\
\hline ST19 & GENE_016121 & chr25 & $1,006,090-1,010,442$ & 1371 & 8 & 456 & 51.17 & 9.32 \\
\hline ST20 & GENE_027595 & chr3 & $8,856,825-8,882,319$ & 1146 & 9 & 381 & 43.22 & 6.03 \\
\hline ST21 & GENE_014314 & contig3637 & $6130-10,174$ & 1032 & 5 & 343 & 37.22 & 8.76 \\
\hline ST22 & GENE_019315 & contig793 & $48,109-52,653$ & 828 & 6 & 275 & 31.70 & 5.84 \\
\hline ST23 & GENE_018873 & chr23 & $7,165,015-7,173,771$ & 1233 & 8 & 410 & 45.28 & 6.29 \\
\hline ST24 & XLOC_010290 & contig1790 & $17,173-23,856$ & 489 & 5 & 162 & 18.81 & 5.42 \\
\hline ST25 & GENE_007603 & chr16 & $3,011,123-3,025,060$ & 1251 & 11 & 416 & 47.56 & 5.68 \\
\hline ST26 & GENE_016729 & chr14 & $16,108,770-16,114,283$ & 1179 & 7 & 392 & 43.69 & 9.83 \\
\hline ST27 & GENE_015508 & chr9 & $15,532,393-15,534,802$ & 867 & 3 & 288 & 22.62 & 6.59 \\
\hline ST28 & GENE_019207 & chr13 & $8,509,051-8,518,818$ & 1254 & 5 & 417 & 46.00 & 9.19 \\
\hline ST29 & GENE_015136 & chr12 & $6,892,181-6,895,811$ & 366 & 4 & 121 & 13.89 & 10.16 \\
\hline ST30 & GENE_007786 & contig317 & $372,098-396,742$ & 1422 & 6 & 473 & 51.37 & 6.15 \\
\hline ST31 & GENE_015734 & contig88 & $64,588-75,181$ & 984 & 8 & 327 & 34.56 & 6.15 \\
\hline ST32 & XLOC_016866 & chr14 & $13,173,117-13,177,606$ & 861 & 6 & 286 & 32.02 & 6.56 \\
\hline ST33 & GENE_000114 & chr16 & $13,476,628-13,492,493$ & 702 & 9 & 233 & 27.31 & 5.37 \\
\hline ST34 & GENE_020104 & contig1359 & $60,122-62,168$ & 549 & 4 & 182 & 21.23 & 4.66 \\
\hline ST35 & GENE_022140 & chr19 & $7,743,111-7,755,418$ & 1386 & 9 & 461 & 51.77 & 9.03 \\
\hline ST36 & GENE_023232 & chr29 & $4,968,806-4,971,862$ & 339 & 2 & 112 & 12.68 & 6.74 \\
\hline ST37 & GENE_023153 & chr20 & $7,032,508-7,047,225$ & 1194 & 6 & 397 & 41.70 & 6.10 \\
\hline ST38 & GENE_019758 & chr15 & $5,177,415-5,200,598$ & 1545 & 12 & 514 & 56.82 & 9.19 \\
\hline ST39 & GENE_017041 & contig1066 & $203,894-217,026$ & 1410 & 5 & 469 & 48.64 & 9.62 \\
\hline ST40 & GENE_009569 & chr14 & $16,256,503-16,263,748$ & 555 & 2 & 184 & 20.32 & 6.08 \\
\hline ST41 & GENE_011849 & chr4 & $12,443,481-12,445,952$ & 447 & 2 & 148 & 16.85 & 9.95 \\
\hline ST42 & GENE_016416 & chr30 & $1,868,233-1,868,544$ & 249 & 1 & 82 & 9.57 & 7.73 \\
\hline ST43 & GENE_020101 & contig1359 & $23,708-25,725$ & 603 & 4 & 200 & 23.70 & 5.44 \\
\hline ST44 & GENE_026033 & chr12 & $3,642,234-3,645,706$ & 1062 & 3 & 353 & 38.47 & 9.22 \\
\hline
\end{tabular}


Additional file 3: Table S3). The ST amino acid sequences in the same group contain similar conserved motifs and indicated that they were highly conserved (Fig. 2a and b). GroupI (25\%) contained Gal-3-O_sulfotr domain (PF06990), group II (13.6\%), III (15.9\%) and V (11.36\%) contained Sulfotransfer_1 domain (PF00685) and Sulfotransfer_3 domain (PF13469), group IV (20.45\%) contained Sulfotransfer-2 domain (PF03567). Motif 1, 16 and 20 were detected to have both Sulfotransfer_1 domain (PF00685) and Sulfotransfer_3 domain (PF13469). Besides, Gal-3-O_sulfotr and Sulfotransfer_3 domain are only present in algae [28].

Gene structure analysis showed that $S T$ gene family included multiple introns. The number of introns ranged from 0 to 12. Each $S T$ contained 6.95 introns on average. Most ST genes $(77.3 \%)$ had more than three introns. Only one gene (ST42) had no introns. The longest intron identified in $S T$ genes was nearly $15 \mathrm{~kb}$ (Fig. 2c).

To study the evolutionary relationship among STs annotated from $S$. japonica and other brown algae, a maximum likelihood (ML) phylogenetic tree was constructed based on the ST amino acid sequences: 44 from $S$. japonica, 41 from E. siliculosus, 24 from C. okamuranus and six from $N$. decipiens (Fig. 3 and Additional file 4: Table S4). Five ST clades were divided, including clade A (24), B (28), C (27), D (15) and E (21), respectively. The group III and V of $44 S T$ genes in S. japonica in Fig. 2 were divided into clade $C$ and showed a closer evolutionary relationship than other groups. STs in the same clade contained same domains. ST5, ST30 and ST39 had far evolutionary distance with other STs in $S$. japonica. Each clade contained STs from S. japonica, E. siliculosus and C. okamuranus. Interestingly, 12 STs of E. siliculosus formed a group between clade A and clade D and contained Sulfotransfer-2 domain (PF03567). STs from $N$. decipiens were only found in clade B, C and E.

\section{Alternative splicing analysis of STs}

We analyzed the types and numbers of all alternative splicing (AS) sites in S. japonica ST genes in different tissues and developmental stages. A total of 217 sites were identified in this gene family. The most abundant AS site type was the alternative transcription start site (TSS) type (72), followed by exon skipping (ES, 52), other (31), p3_splice (21), p5_splice (19), alternative transcription terminal site (TTS, 13) and intergentic (9). Although types and number of AS sites were not uniform in different tissues and developmental stages, some genes centrally contained certain AS types, for example, ST1 (p5_splice), ST3 and ST19 (p3_splice), ST8 (TTS) and ST9 and ST26 (TSS). In the same sample, more AS sites were detected in $S T$ genes with relatively high expression levels. In addition, more AS sites were discovered in basal blade samples than in distal blade. Details of these sites are listed in Additional file 5: Table S5.

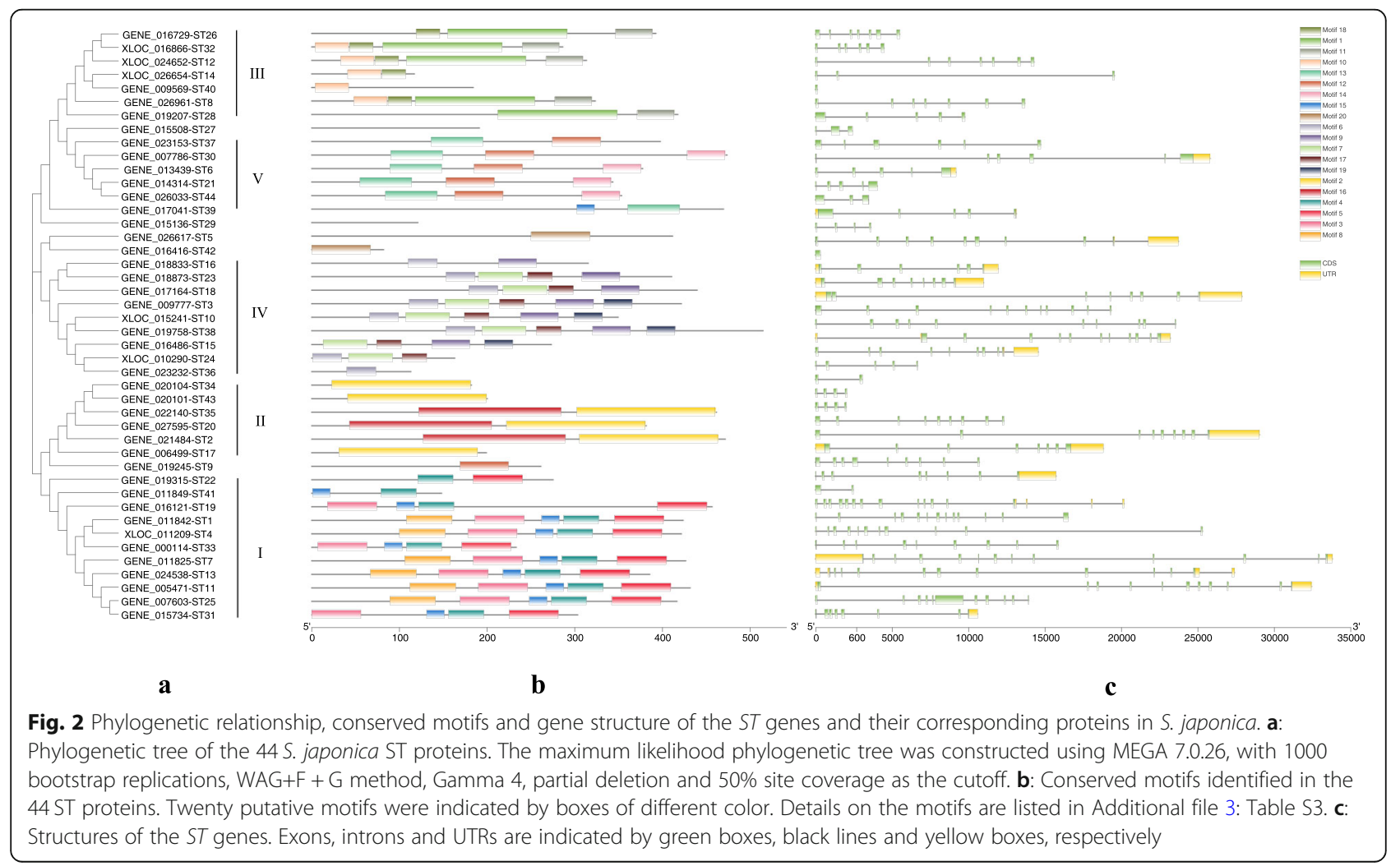




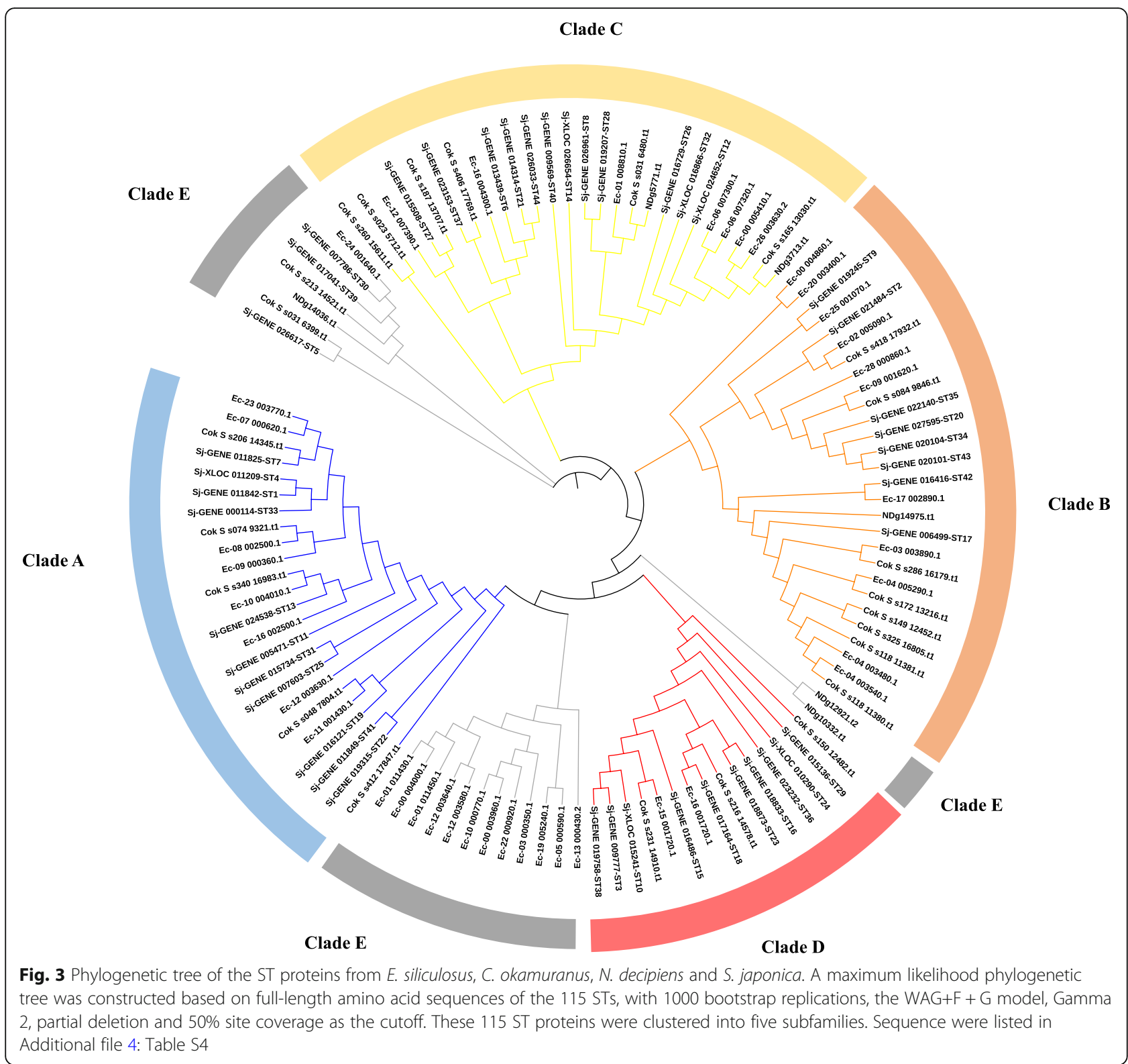

\section{Scaffold location and gene duplication of the STs}

$S T$ genes loci distributed randomly and dispersedly on 17 scaffolds and 11 contigs in S. japonica genome (Fig. 4). Scaffold 4 and 14 contained five and four ST loci, respectively. Although the generation of gene family was usually attributed to tandem duplication and segmental duplication [29], the $S T$ family only contained tandem duplication and these five pairs of genes covered $27.3 \%$ of the whole $S T$ gene family. Genes in the same tandem duplicated pair were located in the same scaffold or contig and demonstrated close physical distance. Usually, there is only one sequence on a chromosome, or two sequences distantly appeared on the same chromosome. Duplicated ST gene pairs were found on scaffold 15 (ST3 and ST38), 23 (ST16 and ST23) and contig1359 (ST34 and ST43).
Two groups of three tandem duplicated genes, ST1, ST4 and ST7 were identified on scaffold 4, and ST14, ST26 and ST32 were identified on scaffold 14 . We found highly similar gene structure, conserved motif and protein secondary structure (Fig. 5) in the same pairs of tandem duplicated genes. No collinearity among $S T$ family members was observed with MCScanX.

\section{Secondary structure analysis of ST proteins}

The secondary structure of protein mainly refers to the main peptide chain curls and folds regularly with hydrogen bond to form a conformation with periodic structure along one-dimensional direction. We used SOPMA to predict the protein structure of STs and found four secondary structures, which randomly distributed in all 


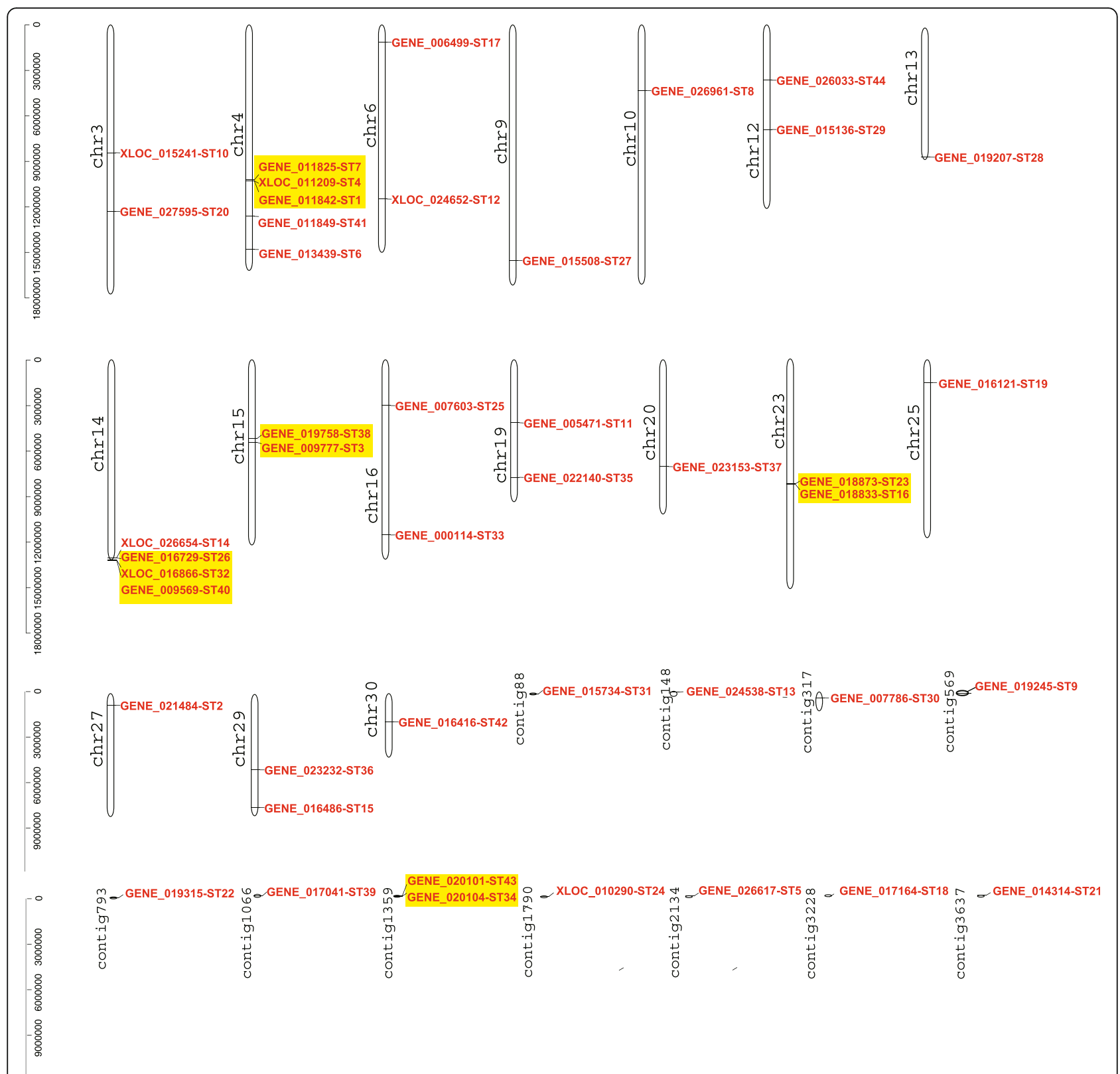

Fig. 4 Scaffold locations of the ST genes and identification of duplicate genes. Tandem duplicated genes are indicated by yellow background

peptide chain, including alpha-helix, extended strand, beta-turn and random coil (Additional file 6: Table S6). Alpha-helix and random coil were the major components of secondary structure and accounted for 41.91 and $39.87 \%$ on average, respectively. The proportion of extended strand was $12.58 \%$. The least was beta-turn, only $5.65 \%$. In five groups of Fig. 2, the proportion of alphahelix of group III was the lowest, only $34.19 \%$, while other four groups contained more than 40\% alpha-helix. Genes in same tandem duplicated pairs (Fig. 4) showed similar proportions of these four secondary structures. Figure 5 shows the representative secondary structures of each group.

\section{Transcriptional profiles of STs in different tissues and developmental stages}

Based on the RNA-Seq data, a heatmap of ST genes under various tissues and developmental stages was illustrated by TBtools (Fig. 6). In the tested samples, ST1 to ST36, ST38 and ST39 were expressed at least in one tissues or developmental stage, and ST1 to ST10 were always highly expressed in all samples. In contrast, the 


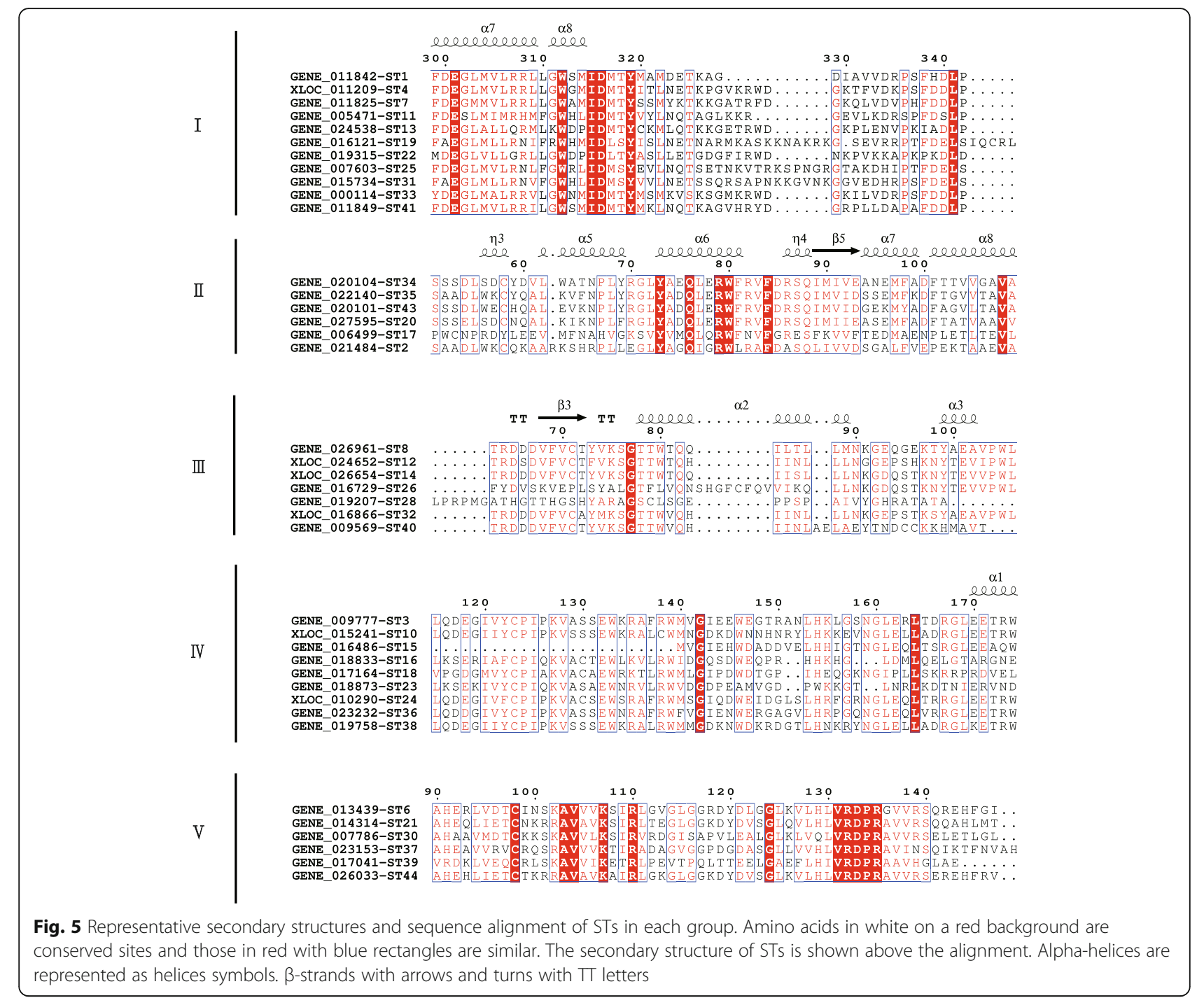

FPKM values of ST37 and ST40 to ST44 were zero all the time. In different developmental stages, ST1, ST17 and ST25 were obviously down-expressed, while ST5, ST15 and $S T 28$ were markedly up-expressed. From basal to distal blade, ST11, ST15 and ST21 had a down-regulation trend, while ST30 and ST24 showed an up-regulation trend. More than half of the STS (54.5\%) were more expressed in the basal than in the distal blade. The expression levels of ST13, ST16 and ST19 had no significant change. It is noteworthy that three out of five pairs of tandem duplicated genes $(S T 1,4,7$; ST14, 26, 32; ST16, 23) showed similar expression trend, except for ST34, ST43 and ST38 with the too low expression level to be detected.

\section{Validation of qualification of RNA-Seq}

We randomly selected three ST genes (GENE_011842, GENE_013439 and GENE_014314) for PCR amplification. The sequences of these three STs cloned from $S$. japonica cDNA templates showed that its genome and
RNA-Seq databases were reliable (Additional file 7: Table S7). qRT-PCR was used to verify the transcript profiles of the four target $S T$ genes with relatively high expression levels (GENE_011842, GENE_021484, GENE_ 009777 and XLOC_011209) involved in fucoidan biosynthesis. The qRT-PCR results and those of RNA-Seq were also consistent (Fig. 7). These two results indicated the reliability of our genome assembly and RNA-Seq data.

\section{Trend analysis and functional enrichment of DEGs}

The trends of transcriptional levels of the $S T$ genes in $S$. japonica basal blade from January to June are shown in Table 2. The STs exhibited several major expressed patterns: profile0 (ST8, ST17, ST18, ST21 and ST25), profile2 (ST6, ST24 and ST32), profile3 (ST1, ST9 and ST30), profile6 (ST12 and ST20), profile25 (ST11), profile28 (ST23) and profile29 (ST5 and ST28) (Table 2). Profile 0 and 29 are the two representative profiles, the former contains genes with a down-regulated expression 


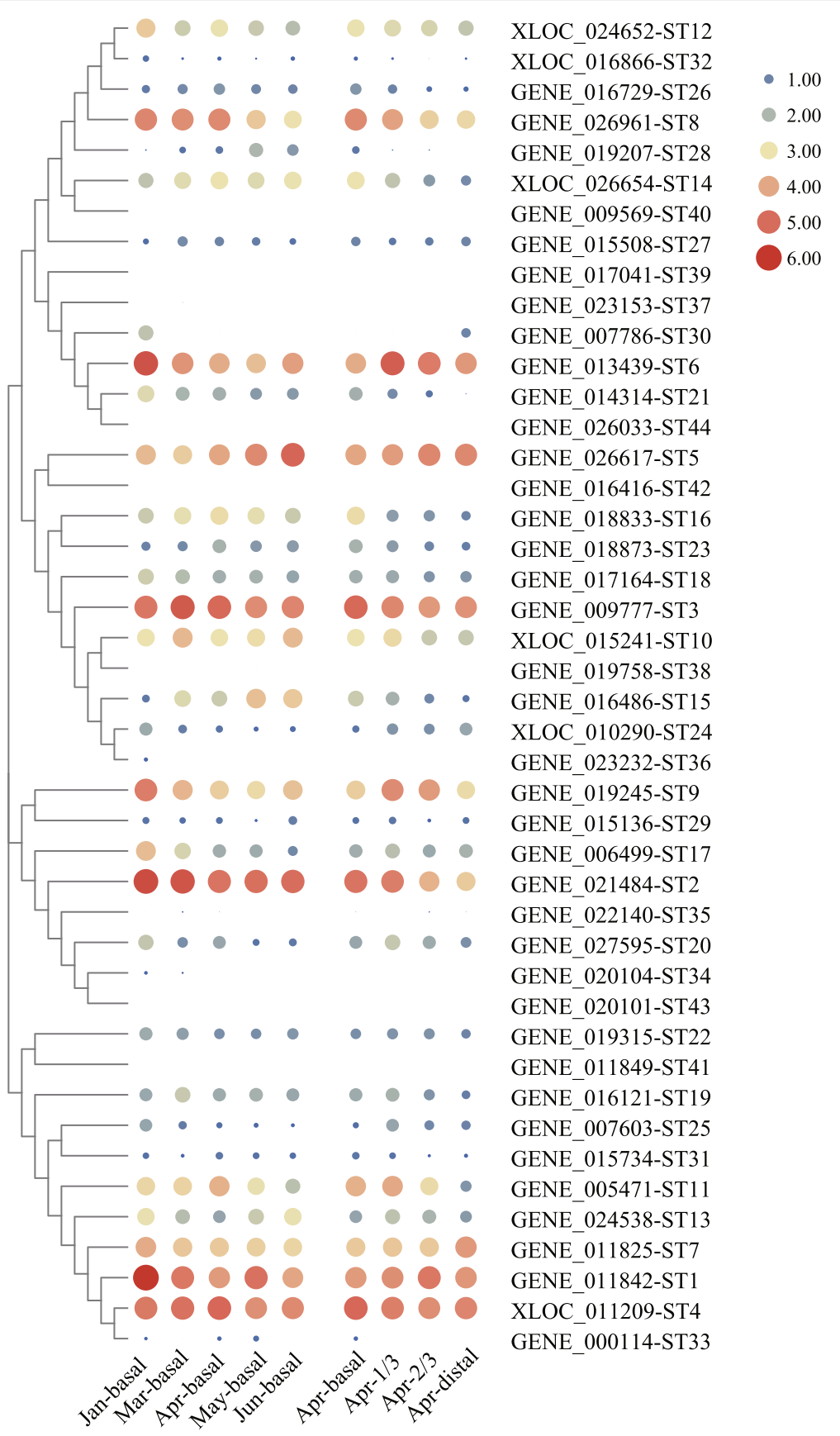

Fig. 6 Transcript profiles of the S. japonica ST genes in different tissues and developmental stages. The larger the circle, the higher the gene expression. If the expression of one gene detected at a time point was 0 , the corresponding position was blank. The heatmap was constructed by TBtools

pattern from January to June while the latter had an upregulated trend. The most enriched pathways in profile 0 included photosynthesis, carbon fixation and metabolic pathway. Genes involved in ribosome, nitrogen metabolism, sulfur metabolism and inositol phosphate metabolism were enriched in profile 29 (Additional file 8: Table S8).

We then analyzed the transcriptional levels of the $S T s$ in different tissues: distal blade, 1/3,2/3 and basal blade of $S$. japonica collected in April (Table 3). According to our results, the STs exhibited five major expression patterns: profile0 (ST14, ST15 and ST23), profile1 (ST8 and ST26), profile 3 (ST28), profile4 (ST16), profile9 (ST2, ST11, ST19 and ST21) and profile17 (ST20). The transcriptional levels of most STs were decreased, as observed for profiles $0,1,4$ and 9 , and genes related to basal metabolism and photosynthesis were enriched in these profiles (Additional file 9: Table S9). 


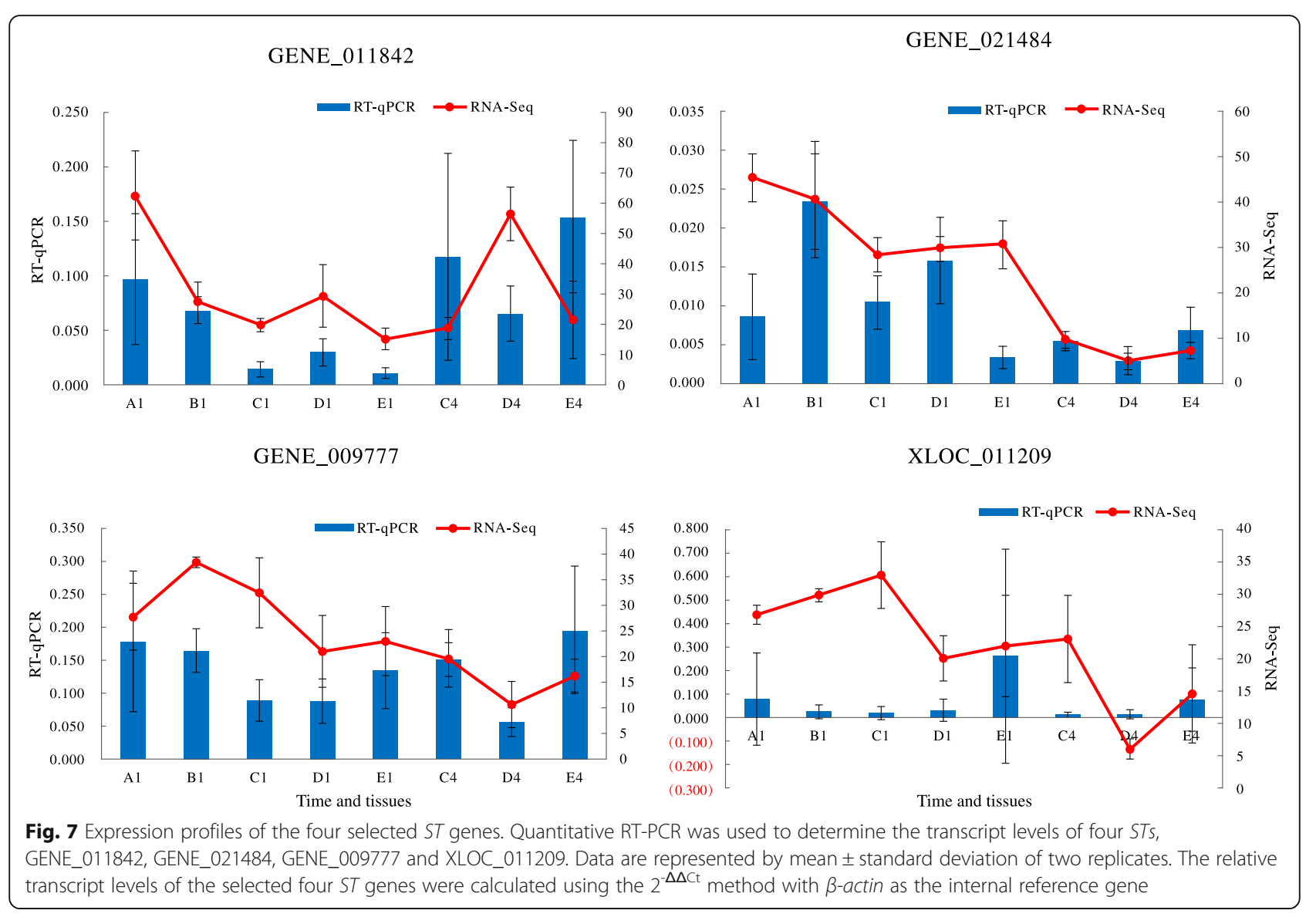

\section{Expression profiles of ST genes under abiotic stress}

We used qRT-PCR to explore the variations of STs expression levels under low salinity and drought stresses. As shown in Fig. 8, ST genes were observed to be up-regulated under low salinity and drought conditions (Fig. 8a and b). These genes reached peak of expression at different treated time points. Under low salinity condition, ST44 had the highest expression level at $0.5 \mathrm{~h}$; ST1, ST2, ST11, ST12, ST31, ST32 and $S T 39$ at $1.5 \mathrm{~h}$; and $S T 21$ at $2.5 \mathrm{~h}$. Additionally, the expression levels of ST1, ST11, ST12 and ST31 were up-regulated by more than four-fold at $1.5 \mathrm{~h}$. ST12 was the most up-regulated gene, and its expression level was 30 -fold higher than that in the control group at $1.5 \mathrm{~h}$. After drought treatment, the expression of all selected $S T s$ was significantly up-regulated. Most STs showed the highest expression level at 0.5 h. ST2 and ST44 reached peak at $1.5 \mathrm{~h}$. The expression levels of ST21, ST31, ST39 and ST44 increased by more than four-fold at $0.5 \mathrm{~h}$. As the most significant up-regulated gene, ST44 was 67 -fold as high as control group at $1.5 \mathrm{~h}$. Under low salinity stress, the expression levels of most $S T$ genes reached peak at
$1.5 \mathrm{~h}$ and $S T$ genes with high expression levels under normal condition were higher expressed. However, under drought stress, the highest STs expression levels mainly appeared at $0.5 \mathrm{~h}$ and $S T s$ with low expression levels in normal showed higher expression levels. The results showed that ST was more positively response to drought than low salinity stress.

\section{Discussion}

In brown algae, sulfotransferase (ST) catalyzes the sulfation reaction in fucoidan biosynthesis, which determines the number and position of sulfate groups and is thus responsible for the various bioactivities of fucoidan. In this study, we retrieved $44 S T$ genes by screening the $S$. japonica genome and transcriptome databases and analyzed their structure, scaffold locations, phylogeny, duplication patterns and expression profiles in different tissues, developmental stages and under abiotic stresses. This study provides valuable information of the $S T$ gene family and facilitates future studies on their functional divergence in brown algae. 
Table 2 Transcript profiles of the S. japonica ST genes during different development stages

\begin{tabular}{lll}
\hline Gene ID & Profile & Details \\
\hline GENE_026961-ST8 & Profile 0 \\
GENE_006499-ST17 & & \\
GENE_017164-ST18 & \\
GENE_014314-ST21 & \\
GENE_007603-ST25 &
\end{tabular}
XLOC_010290-ST24 XLOC_016866-ST32

Profile 2

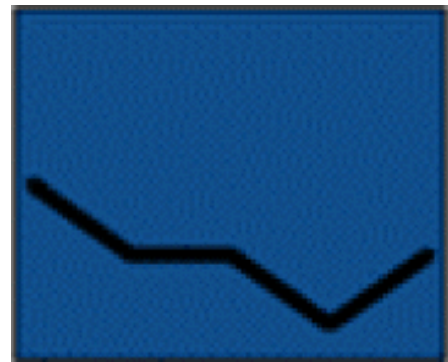

GENE_011842-ST1

GENE_019245-ST9

GENE_007786-ST30

Profile3

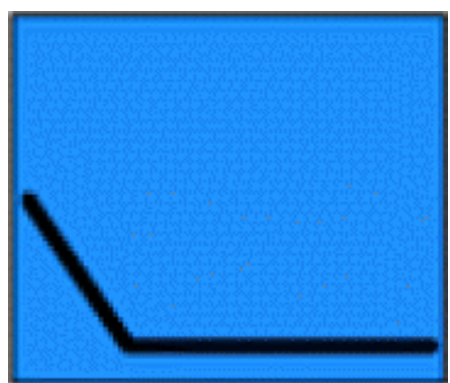

GENE_026617-ST5

GENE_019207-ST28

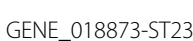

Profile28

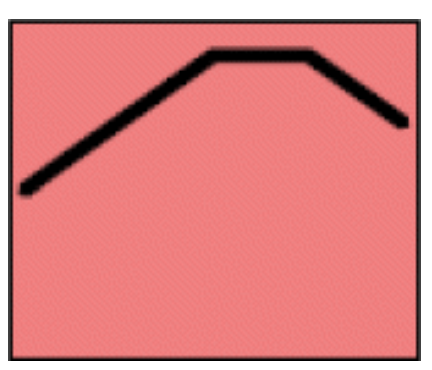

Profile29

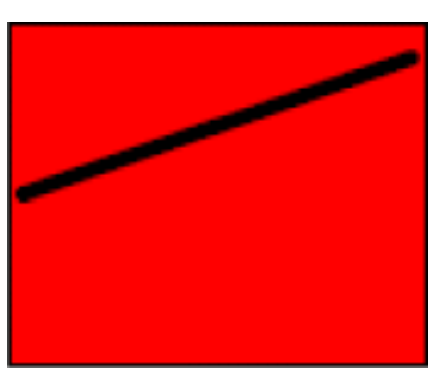

GENE_024538-ST13

Profile 1

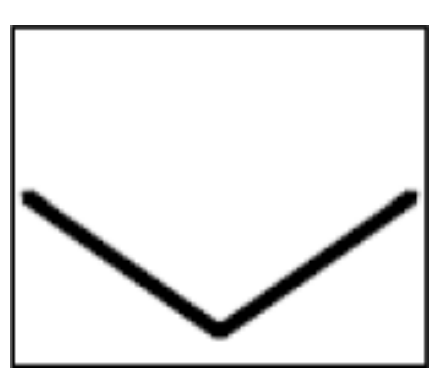

GENE_000114-ST33 Profile 8

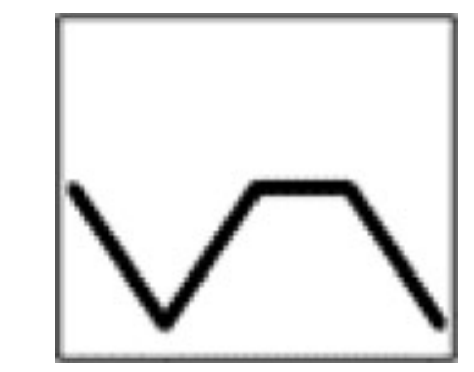

XLOC_024652-ST12

Profile6

GENE_027595-ST20

GENE_005471-ST11

Profile25

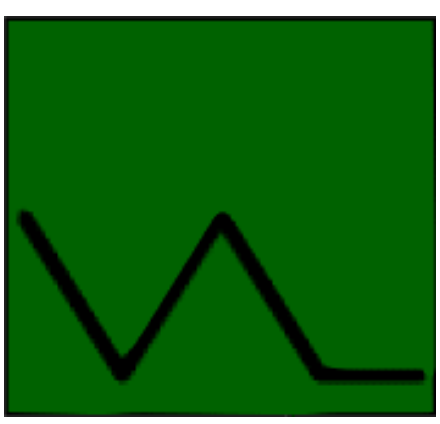
different development stages (Continued)

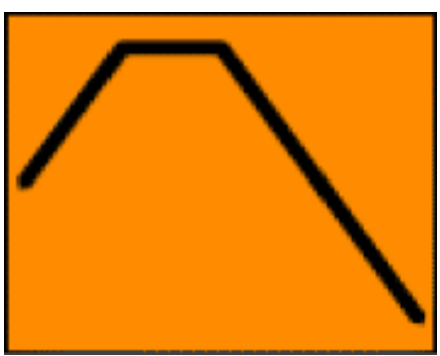

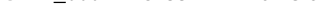


Table 3 Transcript profiles of the ST genes in different S. japonica tissues

\begin{tabular}{lll}
\hline Gene ID & Profile & Details \\
\hline XLOC_026654-ST14 & Profile 0 & \\
GENE_016486-ST15 & & \\
GENE_018873-ST23 & & \\
& &
\end{tabular}

GENE_026961-ST8

GENE_016729-ST26

GENE_019207-ST28

GENE_005471-ST11

GENE_016121-ST19

GENE_014314-ST21
Profile 1

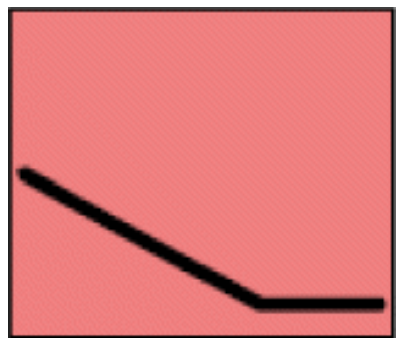

Profile 3

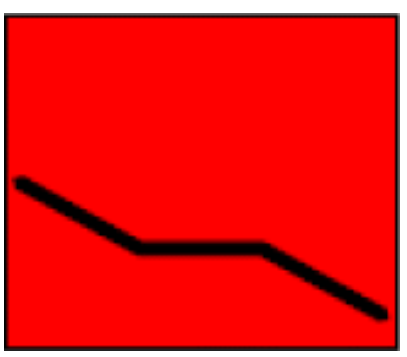

Profile 4

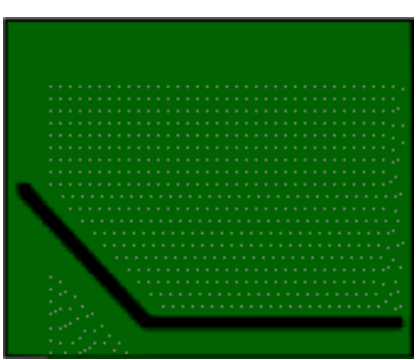

Profile 9

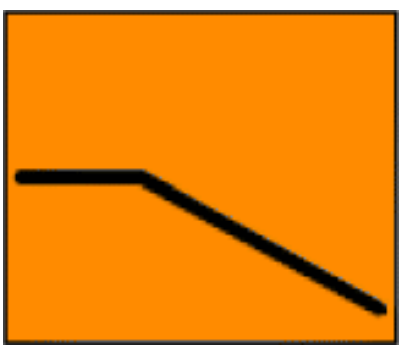


Table 3 Transcript profiles of the ST genes in different S. japonica tissues (Continued)

Gene ID Profile

Profile 10

GENE_015734-ST31

GENE_007786-ST30

GENE_013439-ST6

GENE_019245-ST9

GENE_007603-ST25

Profile 13

Profile 20

Profile 21
Details
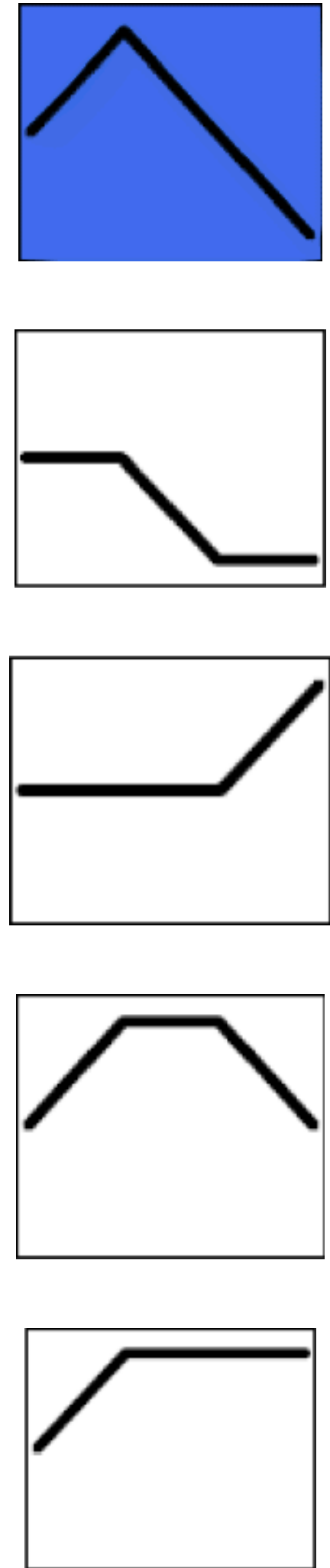


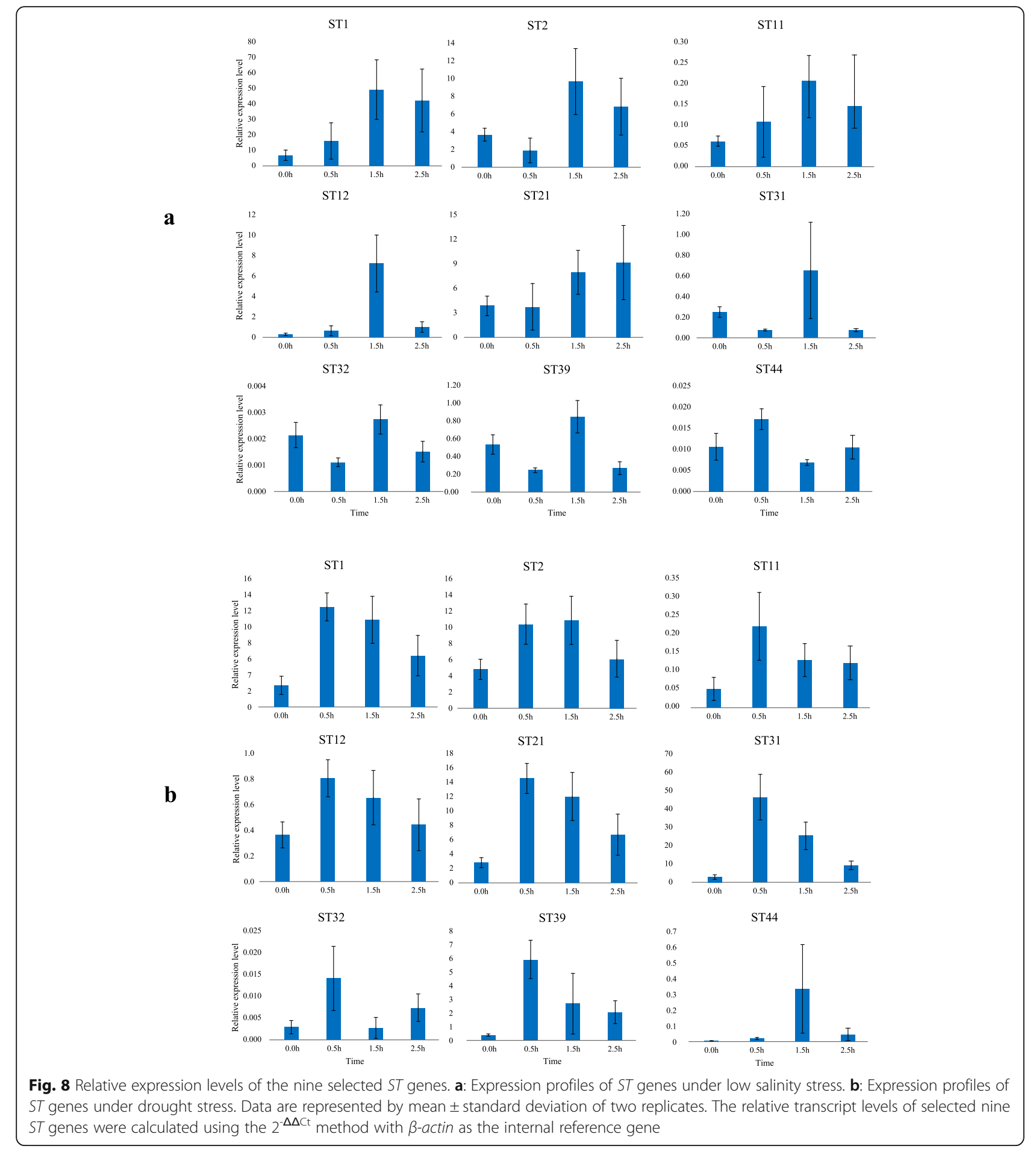

Multiple introns and AS may contribute to the diversity functions of STs

In eukaryotes, the process of AS is differentially spliced primary transcripts of many genes to produce multiple mRNAs. By selectively preserving or removing some exons, a single gene can be transcribed to produce a variety of proteins [30]. Basically, alternative splicing contributed to increased transcriptome and proteome diversity, and genes from most functional categories had high levels of AS [31]. Alternative splicing of intron is considered to regulate gene expression in different time and space [32]. Compared with ST families of Arabidopsis and Oryza sativa, which hardly contained introns [33, 34 , the number of introns in S. japonica ST gene family 
Table 4 Primers used for gene cloning and qRT-PCR

\begin{tabular}{|c|c|c|c|}
\hline Reaction & Gene ID & Forward primer $\left(5^{\prime}-3^{\prime}\right)$ & Reverse primer $\left(5^{\prime}-3^{\prime}\right)$ \\
\hline \multirow[t]{3}{*}{ Genes cloning } & GENE_011842 & ATGGCACGACTCTCTCTCAG & TCAGAACTGGTTCATCGGCGGT \\
\hline & GENE_013439 & ATGTACTGTGTGTATGGCCT & CTACGGTTCATAACCTAGAGCATCC \\
\hline & GENE_014314 & ATGGTGCATGGCTTGGAGTG & CTATAGCTCATAACCTAGAG \\
\hline \multirow[t]{11}{*}{ qRT-PCR } & GENE_011842 & GAAACAAAACGGGGTGGACG & GGTCCGTGGTTGCTACTGAA \\
\hline & GENE_021484 & GCTGATAGTGGTGGACTCGG & CATGTCGTTGTGGTCGGAGA \\
\hline & GENE_005471 & ACAAGACCGGATCGACAACC & ACTTCTGGCTCTCTTGCGTC \\
\hline & XLOC_024652 & CAAGGGAAGGTGCAACAACG & AGATGTTCGCCTTCGGGTTI \\
\hline & GENE_014314 & TGAAGTCCATTCGCCTCACC & TGTTGTCAGCTTTGACCCGA \\
\hline & GENE_015734 & GCACTATCACATCGGCACCT & GGCTCTCGGAAGATGGTGAC \\
\hline & XLOC_016866 & GCGATTTCGAGACCAGGGAT & GTAGCTCTTGGTGCTCGGTT \\
\hline & GENE_017041 & GCTGACGACGGAGGAGTTAG & CCGTGCAATCCTCAGCCATA \\
\hline & GENE_026033 & CACCACACCAGAGCATCCTT & CGCAGCCTTGTAATCGAAGC \\
\hline & GENE_009777 & GCAATCTTGCTTCTGCGACC & CAATCTCAACACCAACGCCC \\
\hline & XLOC_011209 & TACCTGGCGAAACCACGAAA & TTCATCAAACCGCTCCGTCA \\
\hline
\end{tabular}

was unexpectedly high. Combined with AS that found in this family, we presumed that the occurrence of introns and AS in STs could endow the cells synthesize a variety of ST enzymes with different functions and localization. This theory has been found in previous studies of other proteins. For example, it had been found that two alternatively spliced isoforms of serine-arginine-rich proteins in Arabidopsis thaliana, which were generated by 3' _splice, had distinct biological functions in plant development [35]. In plants and animals, the frequencies of AS types were decided by differences in their pre-mRNA splicing [36]. The organisms which contain large introns usually use an exon definition mechanism that results in exon skipping [37]. We correspondingly detected about $24 \%$ exon skipping (ES) sites in ST gene family and no intron retention (IR). Therefore, the type and quantity of the AS in STs are affected by the number of introns to some extent. We suggest that the production of multiple introns and AS is a developmental and physiological strategy which gradually formed in the evolution process of $S$. japonica for effective transcription.

\section{Tandem duplication has important sense in the expansion of ST gene family}

Tandem duplication usually occurs in the region of chromosome recombination, forming a cluster of homologous genes with similar sequence and function, which arrange on the chromosome in a way of head and tail tandem. As a result, the number of one chromosome increases and the other decrease. This mechanism plays an indispensable role in the emergence of clustered genes [38]. Consistent with this conclusion, all the detected tandem duplicated $S T$ genes appear in cluster, while other $S T$ genes tend to appear alone. Tandem duplication tend to amplify dose insensitive genes and genes at the top or end of the metabolic pathway [39], which are also closely related to the amplification of genes related to biotic and abiotic stresses [40]. For example, Teng et al. (2017) found tandem duplication event of lipoxygenase gene family in S. japonica [41]. Considering the above theories, tandem duplication events may be significant in S. japonica ST gene family expansion.

\section{The members of ST gene family may have different protein structures and functions}

Another observation is that similar motif organization only occurred in the same evolutionary subgroup of S. japonica ST genes. STs with highly similar motif distribution might produce similar three-dimensional structure and exercise similar functions. The different distribution of motifs between subgroups may further illustrate the various functions of $S T$ genes.

From the phylogenetic tree of 115 STs, we observed that STs from different brown seaweeds could be found in each clade. This is consistent with their closer evolutionary relationships. Ye et al. (2015) had a similar report on the study of vBPO gene family [12]. Clade E contained the least STs from S. japonica, which may suggest the existence of gene loss evens in S. japonica ST gene family [42]. Twelve STs in E. siliculosus and two STs in N. decipiens clustered and formed two independent subgroups, which may due to their special functions or more independent evolutionary relationship. 
Different expression patterns of STs might meet the needs of growth and development of $S$. japonica in different environments

The expression levels of STS varied obviously in various developmental stages and tissues. Considering the monthly changes in the content of sulphate of fucoidan [43], multiple expression patterns may indicate the synthesis of fucoidan with different sulfated degree. As the concentration of sulfated polysaccharide and its sulphate degree had a positive correlation with salinity in halophytic species [44], we thought this change may be meaningful for S. japonica adapting coastal environment.

Previously, it was hypothesized that sulfotransferasemediated sulfation affects the bioactivity of certain compounds, thereby modulating physiological processes to adapt to abiotic stresses [45]. Teng et al. (2017) found that the expression of a $S T$ gene of E. siliculosus was upregulated under low salinity stress condition [46]. In our study, the up-regulated $S T$ genes $(S T 1,2,11,12,21,31$, $32,39,44)$ under abiotic stresses illustrated that they are a kind of stress resistance gene in S. japonica. In brown algae, fucose-containing sulfated polysaccharide not only activates as cell walls matrix, but also may have a significant role in coping with osmotic stress [14, 47]. Combined the above theories and RNA-Seq and qRT-PCR results, we inferred that a part of $S T$ genes (e.g. $S T 1, S T 2, S T 3$ ) are highly expressed in S. japonica grown at normal condition, which are necessary to maintain the basic needs of growth and development of S. japonica. Meanwhile, the other members (ST39 and ST44) are remarkably upregulated to synthesize fucoidans with high-degree sulfation in response to abiotic stresses, although they exhibit very low expression levels under normal conditions. Therefore, these genes with strong response can be used as the key candidate genes for further functional study on abiotic stress resistance. STs reached the peak expression levels at different treated time. This phenomenon implies that different STs had different response and regulation mechanisms. Various expression patterns are beneficial for $S$. japonica to maintain osmotic pressure stability in response to low salt stress and to keep algae moist in case of drought. Therefore, ST genes family is of great significance for $S$. japonica to adapt to the complex and changeable marine environment.

\section{Conclusions}

A total of $44 S T$ genes which can be divided into five subgroups were identified through analyzing the genome and transcriptome database of S. japonica. Subsequently, these genes were analyzed from gene structure, phylogeny, scaffold location, secondary structures, gene duplication, alternative splices and expression patterns in different tissues, periods and under abiotic stresses. The alternative splice events and introns make the formation of more ST with different function and location become possible. The variable expression patterns of ST genes may contribute to the monthly-changed degree of sulfation of fucoidan and be significant for S. japonica adapting coastal environment. Also as a kind of stress resistance gene, the existence of $S T$ genes is important for $S$. japonica to adapt to changeable marine habitats during whole developmental periods. Our report will be important to future functional verification for the $S T$ genes and potential biochemical manipulation to fucoidan in vitro in the future.

\section{Methods}

\section{Algal sample collection and treatment}

S. japonica sporophytes were collected in December 8th, 2019 from cultivated rafts in Gaolv Aquatic Company in Rongcheng, Shandong, China. All robust samples of similar size were treated overnight in $10^{\circ} \mathrm{C}$ incubator without light. For low salinity stress, sporophytes were cultured in $16 \%$ salinity seawater for $0 \mathrm{~h}, 0.5 \mathrm{~h}, 1.5 \mathrm{~h}$ and $2.5 \mathrm{~h}$. For drought stress, sporophytes were exposed in air for $0 \mathrm{~h}, 0.5 \mathrm{~h}, 1.5 \mathrm{~h}$ and $2.5 \mathrm{~h}$. Three robust individuals were set as biological repeats for each time point, rinsed with filtered seawater several times. Each sectioned tissue samples was snap frozen in liquid nitrogen, and stored at $-80^{\circ} \mathrm{C}$ until total RNA isolation.

Retrieval of fucoidan biosynthetic pathway in S. japonica We have finished RNA-Seq of S. japonica sporophytes during whole developmental periods [48]. Based on this transcriptome data (NCBI: PRJNA512328) and our previously sequenced $S$. japonica genome (NCBI: MEHQ00000000), we identified 104 genes in fucoidan biosynthetic pathway.

\section{Identification of sulfotransferase family members in $S$. japonica genome}

We searched key word "sulfortransferase" in transcriptome sequences annotation file. As long as the gene annotation result contained "sulfortransferase", this gene can be selected as candidate genes for further identification. In this way, we identified 73 genes automatically annotated as sulfotransferase (ST) genes that catalyze the last step of fucoidan biosynthesis. Firstly, these 73 genes were submitted to local Blast to remove redundant genes. If the result of two nucleotide sequences alignment is more than $99 \%$ identity, we regarded these two as repeated sequence, and only keep the longer sequence. Secondly, the rest of genes were submitted to SMART (http://smart.embl-heidelberg.de/) [49, 50] and Pfam (http://pfam.xfam.org/search) [51] to confirm the presence of the conserved domain with cut-off scorn that E-value $<0.05$, and only genes with sulfotransferase domains were retained. Finally, we ranked and renamed 
the rest 44 genes according to the monthly average genes expression from high to low.

\section{Sequence analysis, chromosomal localization and gene duplication}

The open reading frames (ORFs) of high-confidence $S T$ genes were predicted using ORF finder (https://www. ncbi.nlm.nih.gov/orffinder/). If a sequence was detected more than one ORF, we chose the longest one by default. The ExPASy ProtParam tool (https://web.expasy. org/protparam/) was used to analyze the physical and chemical properties of the deduced ST proteins, including molecular weight (MW), and amino acid (AA) composition. The SignalP-5.0 Server (http://www.cbs.dtu. $\mathrm{dk} /$ services/SignalP/) was used to predict signal peptides [52], and TMHMM (v2.0; http://www.cbs.dtu.dk/ services/TMHMM/) was employed for predicting the transmembrane helices in the proteins. Possible localization to the chloroplast, mitochondrion and cytoplasm was predicted by Target-P (http://www.cbs.dtu. $\mathrm{dk} /$ services/TargetP/) [53].

Structure and conserved motifs of the $S T$ genes was analyzed according to Zhao et al. [42]. The chromosomal positions of the $S T$ genes were acquired by aligning the full-length $S T$ nucleic acid sequences to the $S$. japonica genome. TBtools was used to display the chromosomal positions of STs and their relative physical distances [54].

We used MCScanX to search for duplicate genes in the ST family [55]. All the protein sequences of the coding genes in the kelp genome were compared in pairs. The comparison results were used as the files input to MCScanX software to predict the duplicated genes. The software selected the default standards, which were divided into singleton, tandem, proximal and dispersed duplication and the results were output $[56,57]$.

\section{Identification of alternative splicing events}

Tophat 2.1.1 was used to analyze alternative splicing events in the 44ST genes from RNA-Seq data [58]. We referred to the analysis and classification process of He et al. [59].

\section{Sequence alignment and phylogenetic analysis}

All the $44 \mathrm{~S}$. japonica ST proteins were aligned by MAFFT [60] with the default parameters and showed secondary structures by ESPript 3.0 [61]. To analyze the evolutionary relationships among the $44 \mathrm{STs}$ in $S$. japonica, a maximum likelihood (ML) phylogenetic tree was constructed based on the full length amino acid sequences with MEGA 7.0.26 using the WAG+G + F model with 1000 bootstrap replications, Gamma 4, partial deletion and $50 \%$ site coverage as the cutoff value [62].
The amino acid sequences of STs derived from E. siliculosus (41), C. okamuranus (24), $N$. decipiens (6) and $S$. japonica (44) were subjected to phylogenetic analysis. Details of total 115 sequences are displayed in Additional file 4: Table S4. The maximum likelihood (ML) phylogenetic tree was constructed by MEGA 7.0.26 using the full-length amino acid sequences of 115 ST proteins with 1000 bootstrap replications, the WAG+F + G model, Gamma 2, partial deletion and 50\% site coverage as the cutoff value [62]. By running the program "Find Best DNA / Protein Models" of MEGA 7.0.26, we analyzed and got the best building model and related parameters, namely, the $\mathrm{WAG}+\mathrm{F}+\mathrm{G}$ model we used to construct phylogenetic tree.

\section{Transcript profiling of the ST genes in different tissues and developmental stages}

Differentially expressed genes (DEGs) across samples were identified according to Shao et al. [48]. The transcriptional profiles of the S. japonica ST genes in different tissues and developmental stages were determined, obtained, normalized and clustered [48]. The heatmap of $S T$ gene expression was drawn by TBtools [54].

\section{Total RNA extraction and CDNA synthesis}

Total RNA was extracted using a SPARKeasy Polysaccharide polyphenols/complex plant RNA kit (SparkJade Science Co., Ltd., China). The extracted RNA was quantified using a Nanodrop 2000 Spectrophotometer (Thermo Scientific, USA). First-strand cDNA was synthesized using a SPARKscript II RT Plus Kit (With gDNA Eraser) (SparkJade Science Co., Ltd., China) and stored at $-20^{\circ} \mathrm{C}$ for subsequent analysis. All manipulations were operated following the manufacturers' instructions.

\section{PCR amplification and sequencing of the ST genes}

We randomly selected three genes (GENE_011842, GENE_013439 and GENE_014314) for PCR amplification. Primers used to amplify the full-length cDNA sequences of these three genes are listed in Table 4. PCR amplification was performed using the synthesized cDNA as the template. The $20 \mu \mathrm{L}$ reaction mixture contained $10 \mu \mathrm{L} 2 \times$ Phanta Max Master Mix (Vazyme, China), $3 \mu \mathrm{L}$ template, $1 \mu \mathrm{L}$ of each of the forward and reverse primer $(10 \mu \mathrm{M})$ and $5 \mu \mathrm{L} \mathrm{ddH}_{2} \mathrm{O}$. The reaction mixtures were briefly centrifuged and placed in a thermal cycler (Takara, Japan). The conditions used for PCR were as follows: $95^{\circ} \mathrm{C}$ for 5 min, followed by five cycles of $95^{\circ} \mathrm{C}$ for $15 \mathrm{~s}, 65^{\circ} \mathrm{C}$ for 15 s, $72^{\circ} \mathrm{C}$ for $90 \mathrm{~s}, 30$ cycles of $95^{\circ} \mathrm{C}$ for $15 \mathrm{~s}, 60^{\circ} \mathrm{C}$ for $15 \mathrm{~s}$, $72{ }^{\circ} \mathrm{C}$ for $90 \mathrm{~s}$, and a final extension at $72^{\circ} \mathrm{C}$ for $10 \mathrm{~min}$. The PCR products were purified using the gel-cutting recovery kit (Insight, China) and inserted into TOPO cloning vector using a $5 \mathrm{~min}$ TA/Blunt-Zero Cloning Kit (Vazyme, China). The $5 \mu \mathrm{L}$ ligation mixture contained 
$1 \mu \mathrm{L} 5 \times \mathrm{TA} /$ Blunt-Zero Cloning Mix and $4 \mu \mathrm{L}$ purified PCR products $(40 \mathrm{ng} / \mu \mathrm{L})$. The mixture was briefly centrifuged and incubated at $37^{\circ} \mathrm{C}$ for $10 \mathrm{~min}$.

For transformation, $5 \mu \mathrm{L}$ of each recombinant plasmids was mixed with $50 \mu \mathrm{L}$ Trans1-T1 Phage Resistant Chemically Competent Cell (TRANS, China). The mixture was processed under manufacturers operating manual. Colony PCR was carried out using M13 primers and plasmids were sanger sequenced (Sangon, Shanghai, China). The coding sequences of the three STS are provided in Additional file 7: Table S7.

\section{Verification of target genes by qRT-PCR}

qRT-PCR was used to validate qualification of RNA-seq for four genes (ST1, ST2, ST3 and ST4) and detected the transcript levels of the nine target genes with different FPKM values (ST1, ST2, ST11, ST12, ST21, ST31, ST32, ST39 and ST44) under low salinity and drought stresses. Gene-specific primers used for qRT-PCR were designed using Primer-BLAST (https://www.ncbi. nlm.nih.gov/tools/primer-blast/) (Table 4).

qRT-PCR was performed on a Takara Thermal Cycle Dice $^{\text {Tu }}$ Real Time System (Takara, Japan). A $10 \mu \mathrm{L}$ qRTPCR reaction contained $5 \mu \mathrm{L} 2 \times$ SPARKscript II RT Plus Master Mix (SparkJade Science Co., Ltd., China), $1 \mu \mathrm{L}$ template, $0.2 \mu \mathrm{L}$ of each of the forward and reverse primers $(10 \mu \mathrm{M})$, and $3.6 \mu \mathrm{LddH_{2 }}$ O. Conditions used for qRT-PCR were as follows: $95^{\circ} \mathrm{C}$ for $2 \mathrm{~min} 30 \mathrm{~s}$, followed by 40 cycles of $95^{\circ} \mathrm{C}$ for $10 \mathrm{~s}$ and $60^{\circ} \mathrm{C}$ for $30 \mathrm{~s}$; and one cycle of $95^{\circ} \mathrm{C}$ for $15 \mathrm{~s}, 60^{\circ} \mathrm{C}$ for $60 \mathrm{~s}$ and $72^{\circ} \mathrm{C}$ for $15 \mathrm{~s}$. Three biological repeats and two technical replicates were performed. The relative transcriptional levels of the genes were calculated by the $2^{-\Delta \Delta \mathrm{Ct}}$ method [63], and $\beta$ actin was used as the internal reference [64].

\section{Supplementary information}

Supplementary information accompanies this paper at https://doi.org/10. 1186/s12870-020-02422-3.

\footnotetext{
Additional file 1: Table S1. Genes involved in the biosynthesis of fucoidan in S. japonica.

Additional file 2: Table S2. Subcellular localization prediction of the ST proteins.

Additional file 3: Table S3. The putative motifs of ST proteins.

Additional file 4: Table S4. ST amino acids sequences from all the selected species for phylogenetic analysis.

Additional file 5: Table S5. The types of alternative splicing sites in S. japonica ST genes of all samples.

Additional file 6: Table S6. The proportion of secondary structures of STs in S. japonica.

Additional file 7: Table S7. Sequenced results of cloned and sequenced genes.

Additional file 8: Table S8. Transcriptional profiles enriched pathway in S. japonica different development stages.

Additional file 9: Table S9. Transcriptional profiles enriched pathway in S. japonica different tissues.
}

\section{Abbreviations}

AA: amino acid; DEGs: Differentially expressed genes; ES: Exon skipping; FK: Fucose kinase; FPKM: Fragments per kilobase of transcript per million mapped reads; FUT: Fucosyltransferase; GFPP: GDP-fucose

pyrophosphorylase; GFS: GDP-L-fucoidase synthase; GM46D: GDP-mannose 4, 6-dehydrogenase; IR: Intron retention; ML: Maximum likelihood;

MPG: Mannose-1-phosphate guanylyltransferase; MPI: Mannose-6-phosphate isomerase; MW: Molecular weight; NCBI: National Center for Biotechnology Information; NJ: Neighbor-joining; ORFs: Open reading frames; PAPS: 3'phosphoadenosine 5'-phosphosulfate; PMM: Phosphomannomutase; qRTPCR: Real-time quantitative polymerase chain reaction; ST: Sulfotransferase; TSS: Alternative transcription start site; TTS: Alternative transcription terminal site; UTR: Untranslated Region

\section{Acknowledgements}

We would like to thank Yaya Li and Tenglong Jiao, two technicians in Gene Denovo Biotechnology Co. for their help with bioinformatics analysis. We acknowledge TopEdit LLC for the linguistic editing and proofreading during the preparation of this manuscript.

\section{Authors' contributions}

$\mathrm{CL}, \mathrm{ZS}$ and DD conceived and designed research. $\mathrm{CL}$ and $\mathrm{ZS}$ conducted experiments. PZ contributed to the cultivation and the collection of kelp samples. $\mathrm{CL}$ performed the bioinformatics analysis with the supports of Gene Denovo Biotechnology Co. CL interpreted the data and wrote the manuscript. ZS and DD gave critical revision of the manuscript. All authors have read and approved the manuscript.

\section{Funding}

This work was supported by the National Natural Science Foundation of China (no. 41806175), Marine Biology and Biotechnology Laboratory Youth Foundation (YQ2018NO06), Shandong Key Research and Development Program (2018GHY115023), and Joint Research Project between China and Japan (No. 2017YFE0130900). These funders provided financial support for the purchase of instruments and reagents for research. Each of the funding bodies took part in the design of the study and collection, analysis, and interpretation of data, and the writing of the manuscript.

\section{Availability of data and materials}

The reference genome of S. japonica was released in GenBank at the National Centre for Biotechnology Information (NCBI) with the accession number of MEHQ0000000 (https://www.ncbi.nlm.nih.gov/nuccore/

MEHQ00000000.1/). RNA-Seq data was deposited in the NCBI Sequence Read Archive (SRA) with accession number of PRJNA512328 (https://www.ncbi. nIm.nih.gov/bioproject/PRJNA512328). All of the datasets supporting the results of this article are included within the article and its Additional files. ST sequences of $E$. siliculosus were download from (https://bioinformatics.psb. ugent.be/orcae/overview/Ectsi). ST sequences of N. decipiens and C. okamuranus were download from (https://marinegenomics.oist.jp/gallery/).

\section{Ethics approval and consent to participate}

S. japonica sporophytes "Yanza" were collected from cultivated rafts in Gaolv Aquatic Company in Rongcheng, Shandong, China. All sample collection activities have been approved by the head of the company. Prof. Delin Duan had undertook the formal identification of the plant material used in our study. The remaining samples are kept in our laboratory $-80^{\circ} \mathrm{C}$ refrigerator The authors declare the compliance with institutional, national and international guidelines. The experiment was environmentally friendly and had no negative effects on the local ecosystem.

\section{Consent for publication}

Not applicable.

\section{Competing interests}

The authors declare that they have no competing interests.

\section{Author details}

'Key Laboratory of Experimental Marine Biology, Center for Ocean Mega-Science, Institute of Oceanology, Chinese Academy of Sciences, Qingdao 266071, P. R. China. ${ }^{2}$ Laboratory for Marine Biology and Biotechnology, Qingdao National Laboratory for Marine Science and 
Technology, Qingdao 266237, P. R. China. ${ }^{3}$ University of Chinese Academy of Sciences, Beijing 100049, P. R. China. ${ }^{4}$ Division of Mariculture Ecology and Technology, Yellow Sea Fisheries Research Institute, Chinese Academy of Fishery Sciences, Qingdao 266071, China. ${ }^{5}$ State Key Laboratory of Bioactive Seaweed Substances, Qingdao Bright Moon Seaweed Group Co Ltd, Qingdao 266400, P. R. China.

Received: 23 January 2020 Accepted: 29 April 2020

Published online: 11 June 2020

\section{References}

1. Wijesinghea WAJP, Jeona YJ. Biological activities and potential industrial applications of fucose rich sulfated polysaccharides and fucoidans isolated from brown seaweeds: a review. Carbohyd Polym. 2012;88(1):13-20.

2. Cumashi A, Ushakova NA, Preobrazhenskaya ME, D'Incecco A, Piccoli A, Totani L, Tinari N, Morozevich GE, Berman AE, Bilan MI, Usov Al, Ustyuzhanina NE, Grachev AA, Sanderson CJ, Kelly M, Rabinovich GA, lacobelli S, Nifantiev NE. A comparative study of the anti-inflammatory, anticoagulant, antiangiogenic, and antiadhesive activities of nine different fucoidans from brown seaweeds. Glycobiology. 2007;17(5):541-52.

3. Damonte EB, Matulewicz MC, Cerezo AS. Sulfated seaweed polysaccharides as antiviral agents. Curr Med Chem. 2004;11(18):2399-419.

4. Azevedo TCGD, Bezerra MEB, Santos MGL, Souza LA, Marques $C T$, Benevides NMB, Leite EL. Heparinoids algal and their anticoagulant, hemorrhagic activities and platelet aggregation. Biomed Pharmacother. 2009;63(7):477-83.

5. Thomes P, Rajendran M, Pasanban B, Rengasamy R. Cardioprotective activity of Cladosiphon okamuranus against isoproterenol induced myocardial infarction in rats. Phytomedicine. 2010;18(1):52-7.

6. Wang J, Wang F, Yun H, Zhang H, Zhang QB. Effect and mechanism of fucoidan derivatives from Laminaria japonica in experimental adenineinduced chronic kidney disease. J Ethnopharmacol. 2012;139(3):807-13.

7. Xu YJ, Zhang QB, Luo DL, Wang J, Duan DL. Low molecular weight fucoidan modulates P-selectin and alleviatesdiabetic nephropathy. Int I Biol Macromol. 2016;91:233-40.

8. Berteau O, Mulloy B. Sulfated fucans, fresh perspectives: structures, functions, and biological properties of sulfated fucans and an overview of enzymes active toward this class of polysaccharide. Glycobiology. 2003; 13(6):29R-40R

9. Kylin H. Zur biochemie der meersalgen. Hoppe-Seyler's Zeitschrift fur Physiologische Chemie. 1913;83:171-97.

10. Cock JM, Sterck L, Rouzé P, Scornet D, Allen AE, Amoutzias G, Anthouard V, Artiguenave $F$, Aury JM, Badger JH, Beszteri B, Billiau K, Bonnet E, Bothwell JH, Bowler C, Boyen C, Brownlee C, Carrano CJ, Charrier B, Cho GY, Coelho SM, Collén J, Corre E, Silva CD, Delage L, Delaroque N, Dittami SM, Doulbeau S, Elias M, Farnham G, CMM G, Gschloessl B, Heesch S, Jabbari K, Jubin C, Kawai H, Kimura K, Kloareg B, Küpper FC, Lang D, Bail AL, Leblanc C, Lerouge P, Lohr M, Lopez PJ, Martens C, Maumus F, Michel G, MirandaSaavedra D, Morales J, Moreau H, Motomura T, Nagasato C, Napoli CA, Nelson DR, Nyvall-Collén P, Peters AF, Pommier C, Potin P, Poulain J, Quesneville H, Read B, Rensing SA, Ritter A, Rousvoal S, Samanta M, Samson G, Schroeder DC, Ségurens B, Strittmatter M, Tonon T, Tregear JW, Valentin K, Dassow PV, Yamagishi T, Peer YV, Wincker P. The Ectocarpus genome and the independent evolution of multicellularity in brown algae. Nature. 2010; 465(7298):617-21.

11. Michel G, Tonon T, Scornet D, Cock JM, Kloareg B. The cell wall polysaccharide metabolism of the brown alga Ectocarpus siliculosus. Insights into the evolution of extracellular matrix polysaccharides in eukaryotes. New Phytol. 2010;188(1):82-97.

12. Ye NH, Zhang XW, Miao M, Fan X, Zheng Y, Xu D, Wang JF, Zhou L, Wang DS, Gao Y, Wang YT, Shi WY, Ji PF, Li DM, Guan Z, Shao CW, Zhuang ZM, Gao ZQ, Qi J, Zhao FQ. Saccharina genomes provide novel insight into kelp biology. Nat Commun. 2015;6:6986.

13. Nishitsuji K, Arimoto A, Higa Y, Mekaru M, Kawamitsu M, Satoh N, Shoguchi E. Draft genome of the brown alga, Nemacystus decipiens, Onna-1 strain: fusion of genes involved in the sulfated fucan biosynthesis pathway. Sci Rep. 2019;9:4607.

14. Chi S, Liu T, Wang XM, Wang R, Wang SS, Wang GL, Shan GL, Liu C. Functional genomics analysis reveals the biosynthesis pathways of important cellular components (alginate and fucoidan) of Saccharina. Curr Genet. 2018;64(6):259-73.
15. Zhang PY, Shao ZR, Li L, Liu S, Yao JT, Duan DL. Molecular characterisation and biochemical properties of phosphomannomutase/ phosphoglucomutase (PMM/PGM) in the brown seaweed Saccharina japonica. J Appl Phycol. 2018:30:2687-96.

16. Pomin VH, Pereira MS, Valente A, Tollefsen DM, Pavão MSG, Mourão PAS. Selective cleavage and anticoagulant activity of a sulfated fucan: stereospecific removal of a 2-sulfate ester from the polysaccharide by mild acid hydrolysis, preparation of oligosaccharides, and heparin cofactor IIdependent anticoagulant activity. Glycobiology. 2005;15:369-81.

17. Fernando IPS, Sanjeewa KKA, Samarakoon KW, Lee WW, Kim HS, Kang N, Ranasinghe P, Lee HS, Jeon YJ. A fucoidan fraction purified from Chnoospora minima; a potential inhibitor of LPS-induced inflammatory responses. Int J Biol Macromol. 2017;104:1185-93.

18. Skriptsova AV, Shevchenko NM, Zvyagintseva TN, Imbs TI. Monthly changes in the content and monosaccharide composition of fucoidan from Undaria pinnatifida (Laminariales, Phaeophyta). J Appl Phycol. 2010;22(1):79-86.

19. Li B, Lu F, Wei X, Zhao R. Fucoidan: structure and bioactivity. Molecules. 2008;13(8):1671-95.

20. Morya VK, Kim J, Kim E. Algal fucoidan: structure and size-dependent bioactivities and their perspectives. Appl Microbiol Biotechnol. 2012;93(1): 71-82.

21. Nishino T, Nagumo T. Anticoagulant and antithrombin activities of over sulfated fucans. Carbohydr Res. 1992;229(2):355-62.

22. Chevolot L, Foucault A, Chauber F, Kervarec N, Sinquin C, Fisher AM, BoissonVidal C. Further data on the structure of brown seaweed fucans: relationships with anticoagulant activity. Carbohydr Res. 1999;319(1-4):154-65.

23. Chevolot L, Mulloy B, Ratiskol J, Foucault A. Colliec-Jouault Sylvia. A disaccharide repeat unit is the major structure in fucoidans from two species of brown algae. Carbohydr Res. 2001;330(4):529-35.

24. Yoon SJ, Pyun YR, Hwang JK, Mourão PAS. A sulfated fucan from the brown alga Laminaria cichorioides has mainly heparin cofactor II-dependent anticoagulant activity. Carbohydr Res. 2007;342(15):2326-30.

25. Pereira MS, Melo FR, Mourão PAS. Is there a correlation between structure and anticoagulant action of sulfated galactans and sulfated fucans? Glycobiology. 2002;12(10):573-80.

26. Ho CL. Phylogeny of algal sequences encoding carbohydrate sulfotransferases, formylglycine-dependent sulfatases, and putative sulfatase modifying factors. Front Plant Sci. 2015;6:1057.

27. Nishitsuji K, Arinoto A, Iwai K, Sudo Y, Hisata K, Fujie M, Arakaki N, Kushiro T, Konishi T, Shinzato C, Satoh N, Shoguchi E. A draft genome of the brown alga, Cladosiphon okamuranus, S-strain: a platform for future studies of 'mozuku' biology. DNA Res. 2016;23:561-70.

28. Hirschmann F, Krause F, Papenbrock J. The multi-protein family of sulfotransferases in plants: composition, occurrence, substrate specificity, and functions. Front. Plant Sci. 2014:5:556.

29. Cannon SB, Mitra A, Baumgarten A, Young ND, May G. The roles of segmental and tandem gene duplication in the evolution of large gene families in Arabidopsis thaliana. BMC Plant Biol. 2004;4(1):10.

30. Heyd F. Alternative splicing--principles, functional consequences and therapeutic implications. Deut Med Wochenschr. 2013;139(7):339-42.

31. Irima M, Rukov JL, Penny D, Roy SW. Functional and evolutionary analysis of alternatively spliced genes is consistent with an early eukaryotic origin of alternative splicing. BMC Evo Biol. 2007;7(1):188.

32. Xie XZ, Wu NH. Introns in higher plant genes. Chin Sci Bull. 2002;47:1409.

33. Klein M, Papenbrock J. The multi-protein family of Arabidopsis sulphotransferases and their relatives in other plant species. J Exp Bot. 2004;55(404):1809-20.

34. Chen RJ, Jiang YY, Dong JL, Zhang X, Xiao HB, XU ZJ, Gao XL. Genome-wide analysis and environmental response profiling of SOT family genes in rice (Oryza sativa). Genes Genomics. 2012;34(5):549-60.

35. Zhang XN, Mount SM. Two alternatively spliced isoforms of the Arabidopsis sr45 protein have distinct roles during normal plant development. Plant Physiol. 2009;150(3):1450-8.

36. Reedy ASN, Marquez Y, Kalyna M, Barta A. Omplexity of the alternative splicing landscape in plants. Plant Cell. 2013;25(10):3657-83.

37. Nakai K, Sakamoto H. Construction of a novel database containing aberrant splicing mutations of mammalian genes. Gene. 1994;141(2):171-7.

38. Charlesworth B, Sniegowski P, Stephan W. The evolutionary dynamics of repetitive DNA in eukaryotes. Nature. 1994;317(6494):215-20.

39. Freeling M. Bias in plant gene content following different sorts of duplication: tandem, whole-genome, segmental, or by transposition. Annu Rev Plant Biol. 2009;60:433. 
40. Leister D. Tandem and segmental gene duplication and recombination in the evolution of plant disease resistance genes. Trends Genet. 2004;20(3): $116-22$.

41. Teng LH, Han WT, Fan X, Xu D, Zhang XW, Dittamin SM, Ye NH. Evolution and expansion of the prokaryote-like lipoxygenase family in the brown alga Saccharina japonica. Front Plant Sci. 2017;8:2018

42. Zhao P, Wang DD, Wang RQ, Kong NN, Zhang C, Yang CH, Wu WT, Ma HL, Chen Q. Genome-wide analysis of the potato Hsp20 gene family: identification, genomic organization and expression profiles in response to heat stress. BMC Genomics. 2018;19(1):61.

43. Honya M, Mori H, Anzai M, Araki Y, Nisizawa K. Monthly changes in the content of fucans, their constituent sugars and sulphate in cultured Laminaria japonica. Hydrobiologia. 1999;398-399:411-6.

44. Aquino RS, Grativol C, Mourão PAS. Rising from the sea: correlations between sulfated polysaccharides and salinity in plants. PLoS One. 2011;6(4): e18862

45. Marsolais F, Gidda SK, Boyd J, Varin L. Plant soluble sulfotransferases: structural and functional similarity with mammalian enzymes. Recent Adv Phytochem. 2000;34:433-56.

46. Teng LH, Fan X, Xu D, Zhang XW, Mock T, Ye NH. Identification of genes under positive selection reveals differences in evolutionary adaptation between brown-algal species. Front Plant Sci. 2017:8:1429.

47. Deniaud-Bouet E, Kervaree N, Michel G, Tonon T, Kloareg B, Herve C. Chemical and enzymatic fractionation of cell walls from Fucales: insights into the structure of the extracellular matrix of brown algae. Ann BotLondon. 2014;114(6):1203-16.

48. Shao ZR, Zhang PY, Lu C, Li SX, Chen ZH, Wang XL, Duan DL. Transcriptome sequencing of Saccharina japonica sporophytes during whole developmental periods reveals regulatory networks underlying alginate and mannitol biosynthesis. BMC Genomics. 2019;20:975.

49. Letunic I, Doerks T, Bork P. SMART: recent updates, new developments and status in 2015. Nucleic Acids Res. 2015:43(D1):D257-60.

50. Letunic I, Bork P. 20 years of the SMART protein domain annotation resource. Nucleic Acids Res. 2018:46(D1):D493-6.

51. El-Gebali S, Mistry J, Bateman A, Eddy SR, Luciani A, Potter SC, Qureshi M, Richardson LJ, Salazar GA, Smart A, Sonnhammer ELL, Hirsh L, Paladin L, Piovesan D, Tosatto SCE, Finn RD. The Pfam protein families database in 2019. Nucleic Acids Res. 2019;47(D1):D427-32

52. Armenteros JJA, Tsirigos KD, Sønderby CK, Petersen TN, Winther O, Brunak S, Heijne GV, Nielsen H. SignalP 5.0 improves signal peptide predictions using deep neural networks. Nature Biotechnol. 2019;37(4):420-3.

53. Emanuelsson O, Brunak S, Heijne GV, Nielsen H. Locating proteins in the cell using TargetP, SignalP and related tools. Nat Protoc. 2007;2(4):953-71.

54. Chen CJ, Chen H, He YH, Xia R. TBtools, a toolkit for biologists integrating various biological data handling tools with a user-friendly interface. BioRxiv. 2018;14:48.

55. Wang YP, Tang HB, DeBarry JD, Tan X, Li JP, Wang XY, Lee TH, Jin HZ, Marler B, Guo H, Kissinger JC, Paterson AH. MCScanX: a toolkit for detection and evolutionary analysis of gene synteny and collinearity. Nucleic Acids Res. 2012;40(7):e49

56. Duan WK, Huang ZN, Song XM, Liu TK, Liu HL, Hou XL, Li Y. Comprehensive analysis of the polygalacturonase and pectin methylesterase genes in Brassica rapa shed light on their different evolutionary patterns. Sci Rep-UK. 2016;6:25107.

57. Huang ZN, Duan WK, Song XM, Tang J, Wu P, Zhang B, Hou XL. Retention, molecular evolution, and expression divergence of the auxin/indole acetic acid and auxin response factor gene families in Brassica Rapa shed light on their evolution patterns in plants. Genome Biol Evol. 2016;8(2):302-16.

58. Trapnell C, Pachter L, Salzberg SL. TopHat: discovering splice junctions with RNA-Seq. Bioinformatics. 2009;25(9):1105-11.

59. He B, Hu ZH, Ma L, Li HR, Ai MQ, Han JZ, Zeng B. Transcriptome analysis of different growth stages of Aspergillus oryzae reveals dynamic changes of distinct classes of genes during growth. BMC Microbiol. 2018;18:12.

60. Katoh K, Standley DM. MAFFT multiple sequence alignment software version 7: Improvements in performance and usability. Mol Biol Evol. 2013; 30(4):772-80.

61. Robert $X$, Gouet $P$. Deciphering key features in protein structures with the new ENDscript server. Nucleic Acids Res. 2014;42(W1):W320-4.

62. Kumar S, Stecher G, Tamura K. MEGA7: molecular evolutionary genetics analysis version 7.0 for bigger datasets. Mol Biol Evol. 2016;33(7):1870-4.
63. Schmittgen TD, Zakrajsek BA, Mill AG, Gorn V, Singer MJ, Reed MW. Quantitative reverse transcription-polymerase chain reaction to study mRNA decay: comparison of endpoint and real-time methods. Anal Biochem. 2000; 285:194-204.

64. Shao ZR, Zhang PY, Li QY, Wang XL, Duan DL. Characterization of mannitol2-dehydrogenase in Saccharina japonica: evidence for a new polyol-specific long-chain dehydrogenases/reductase. PLoS One. 2014;9(5):e97935.

\section{Publisher's Note}

Springer Nature remains neutral with regard to jurisdictional claims in published maps and institutional affiliations.
Ready to submit your research? Choose BMC and benefit from:

- fast, convenient online submission

- thorough peer review by experienced researchers in your field

- rapid publication on acceptance

- support for research data, including large and complex data types

- gold Open Access which fosters wider collaboration and increased citations

- maximum visibility for your research: over $100 \mathrm{M}$ website views per year

At BMC, research is always in progress.

Learn more biomedcentral.com/submissions 